\title{
Evaluation of Candidate In-Pile Thermal Conductivity Techniques
}

B. Fox

H. Ban

J. Daw

K. Condie

D. Knudson

J. Rempe

May 2009

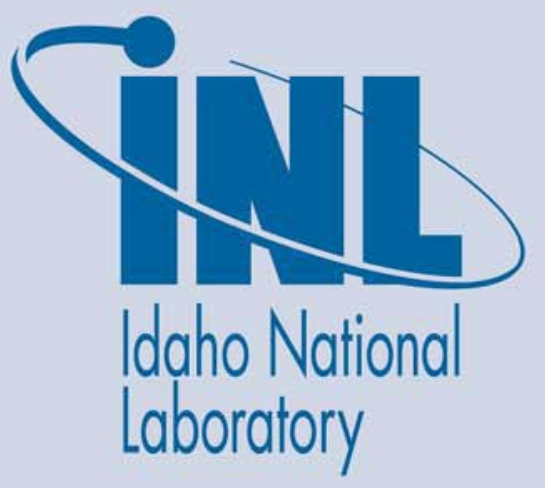

The INL is a U.S. Department of Energy National Laboratory operated by Battelle Energy Alliance 
INL/EXT-09-16039

\title{
Evaluation of Candidate In-Pile Thermal Conductivity Techniques
}

\author{
B. Fox \\ H. Ban \\ J. Daw \\ K. Condie \\ D. Knudson \\ J. Rempe \\ May 2009

\begin{abstract}
Idaho National Laboratory
Idaho Falls, Idaho 83415
\end{abstract} \\ http://www.inl.gov \\ Prepared for the \\ U.S. Department of Energy \\ Office of Nuclear Energy \\ Under DOE Idaho Operations Office \\ Contract DE-AC07-05ID14517
}




\section{CONTENTS}

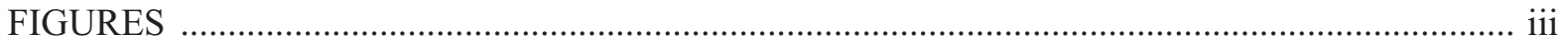

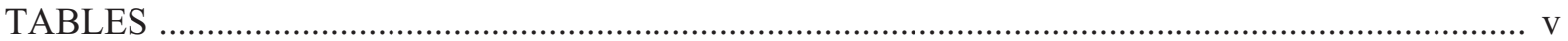

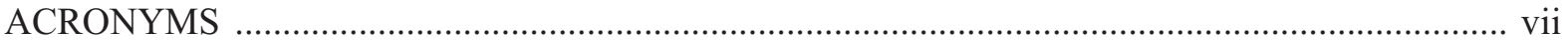

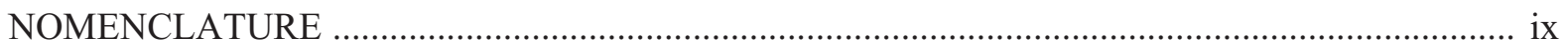

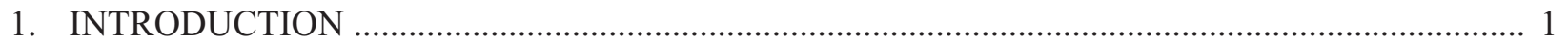

1.1. Research Objectives ..................................................................................................... 1

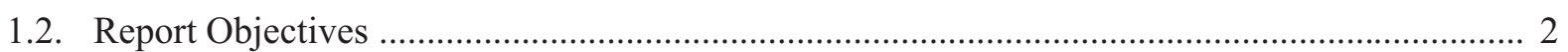

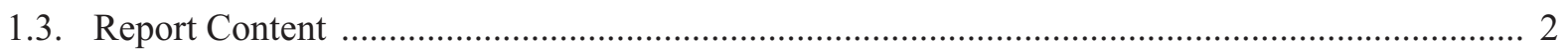

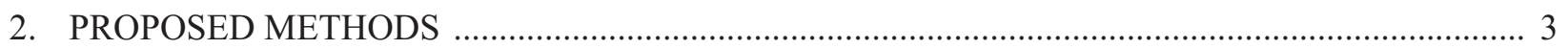

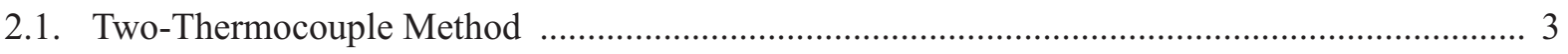

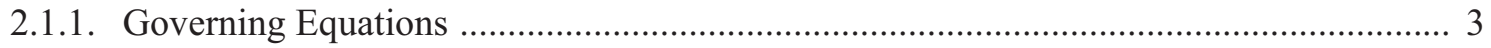

2.1.2. Method Limitations and Uncertainty ……................................................................... 4

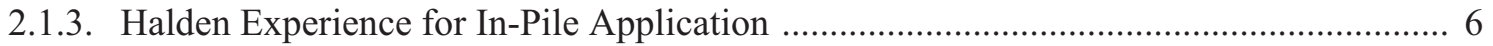

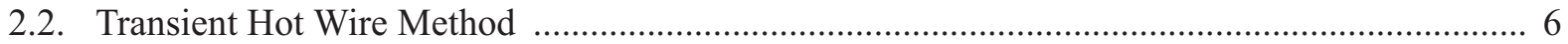

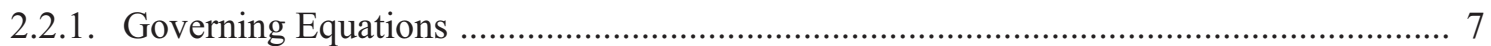

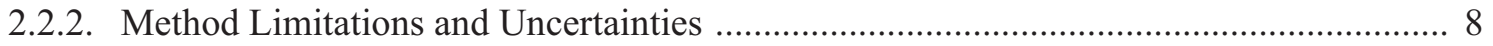

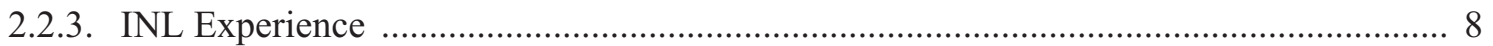

2.3. Surrogate Rod Materials ................................................................................................. 8

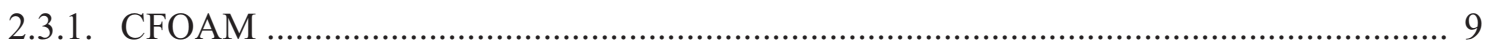

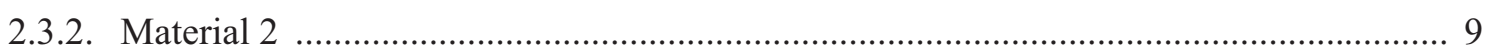

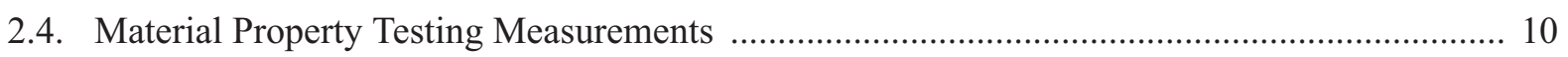

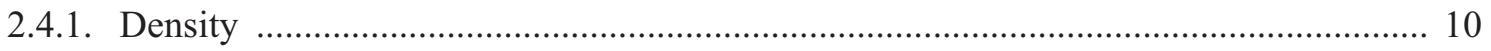

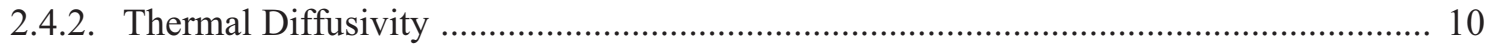

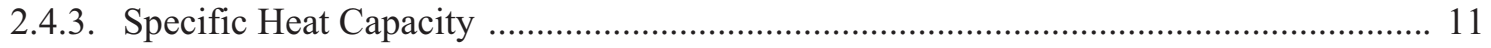

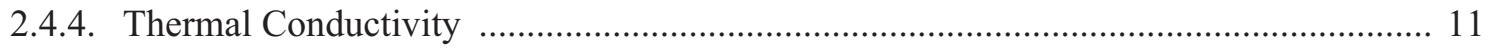

2.5. Finite Element Modeling Using ABAQUS .......................................................................... 11

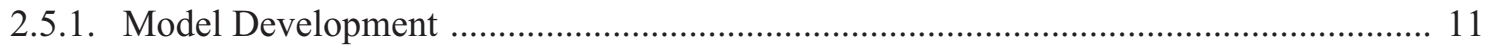

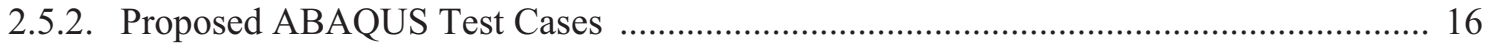

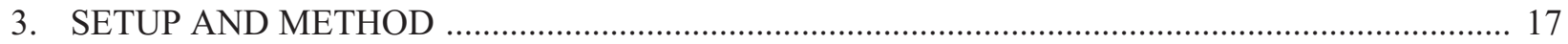

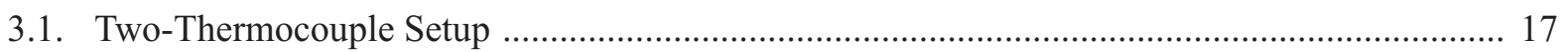

3.1.1. Two-Thermocouple Method Sensitivity Testing ........................................................ 19

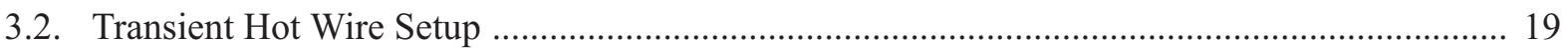




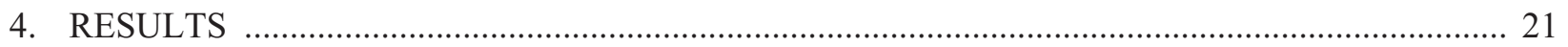

4.1. CFOAM25 Two-Thermocouple Results ........................................................................... 21

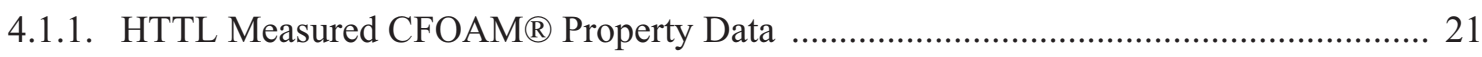

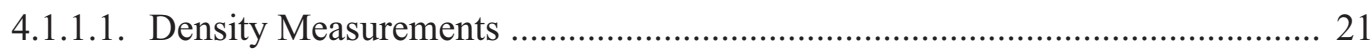

4.1.1.2. Specific Heat Measurements ..................................................................... 22

4.1.1.3. Thermal Diffusivity Measurements ............................................................ 23

4.1.1.4. Thermal Conductivity From Material Properties Data .................................. 23

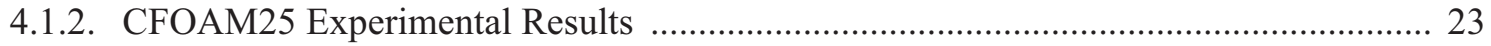

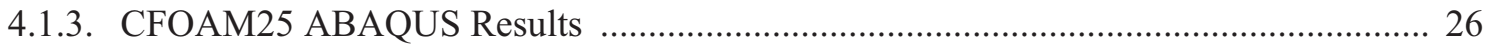

4.1.3.1. Base Case Results for $40 \mathrm{~W}$ and $100 \mathrm{~W}$....................................................... 26

4.1.3.2. Gap Conductance Sensitivity ....................................................................... 27

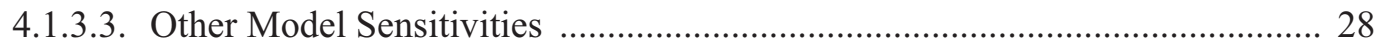

4.2. Material 2 Two-Thermocouple Results .................................................................................. 28

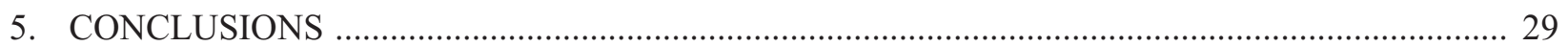

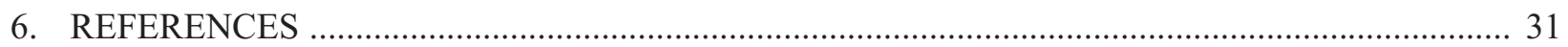

INL/EXT-09-16039 ii 


\section{FIGURES}

2-1. Solid cylinder heat conduction with uniform heat generation ................................................... 3

2-2. Halden generated plot of fuel thermal conductivity as a function of rod burn-up ${ }^{8}$......................... 6

2-3. Typical time versus temperature plot for hot wire method ........................................................ 7

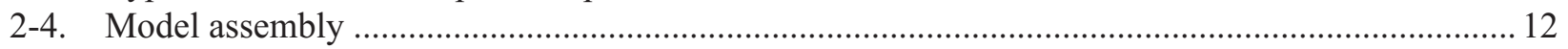

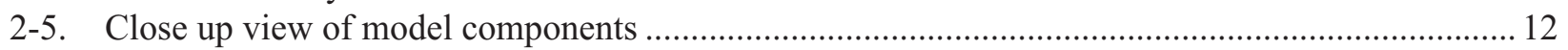

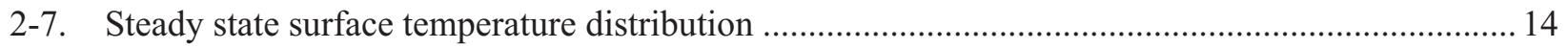

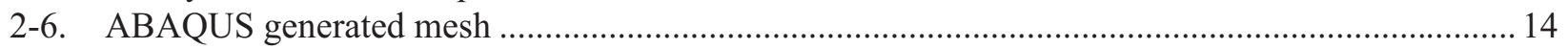

2-8. Cutaway model view with thermocouple junctions highlighted.............................................. 15

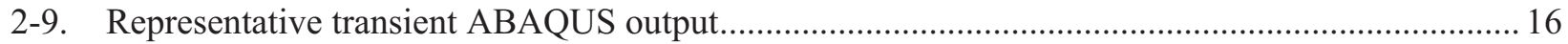

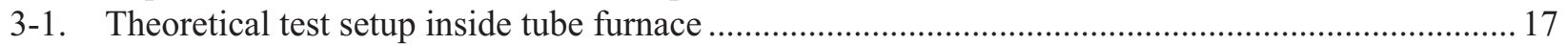

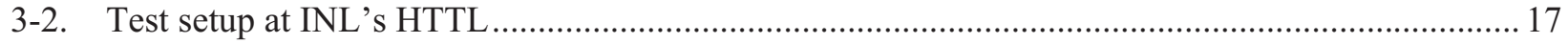

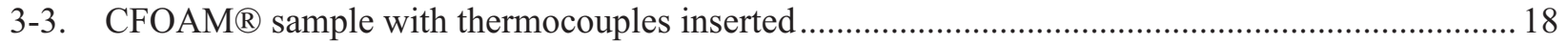

4-1. CFOAM25 average density versus temperature with upper and lower bounds............................2 21

4-2. CFOAM25 average specific heat, $\mathrm{Cp}$, vs. temperature with upper and lower bounds ..................... 22

4-3. Average CFOAM25 thermal diffusivity vs. temperature with upper and lower bounds................. 23

4-4. Two-thermocouple approach CFOAM25 outer thermocouple down experimental data.................. 24

4-5. Two-thermocouple approach CFOAM25 outer thermocouple up experimental data ..................... 24

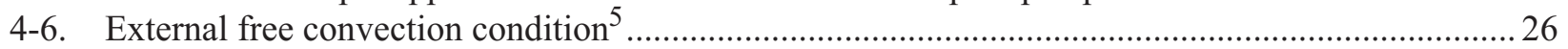

4-7. ABAQUS model base case CFOAM25 thermal conductivity outputs ...................................... 27

4-8. ABAQUS results compared to HTTL measured material properties ..........................................28 
INL/EXT-09-16039 


\section{TABLES}

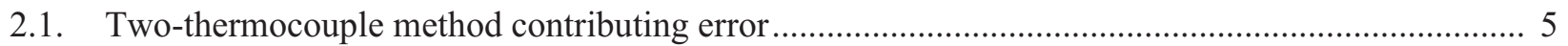

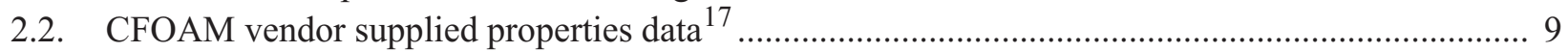

2.3. Proposed testing variations for two-thermocouple model ....................................................... 16

3.1. Proposed testing variations for steady state conditions.......................................................... 19 
INL/EXT-09-16039 


\section{ACRONYMS}

USU - Utah State University

INL - Idaho National Laboratory

IFE - Institutt for Energiteknikk

HBWR - Halden Boiling Water Reactor

THWM - Transient Hot Wire Method

ASTM - American Standard Test Method

HRP - Haldenprosjektet

HTTL - High Temperature Test Laboratory

DSC - Differential Scanning Calorimeter

FEA - Finite Element Analysis

W - Watts 
INL/EXT-09-16039 


\section{NOMENCLATURE}

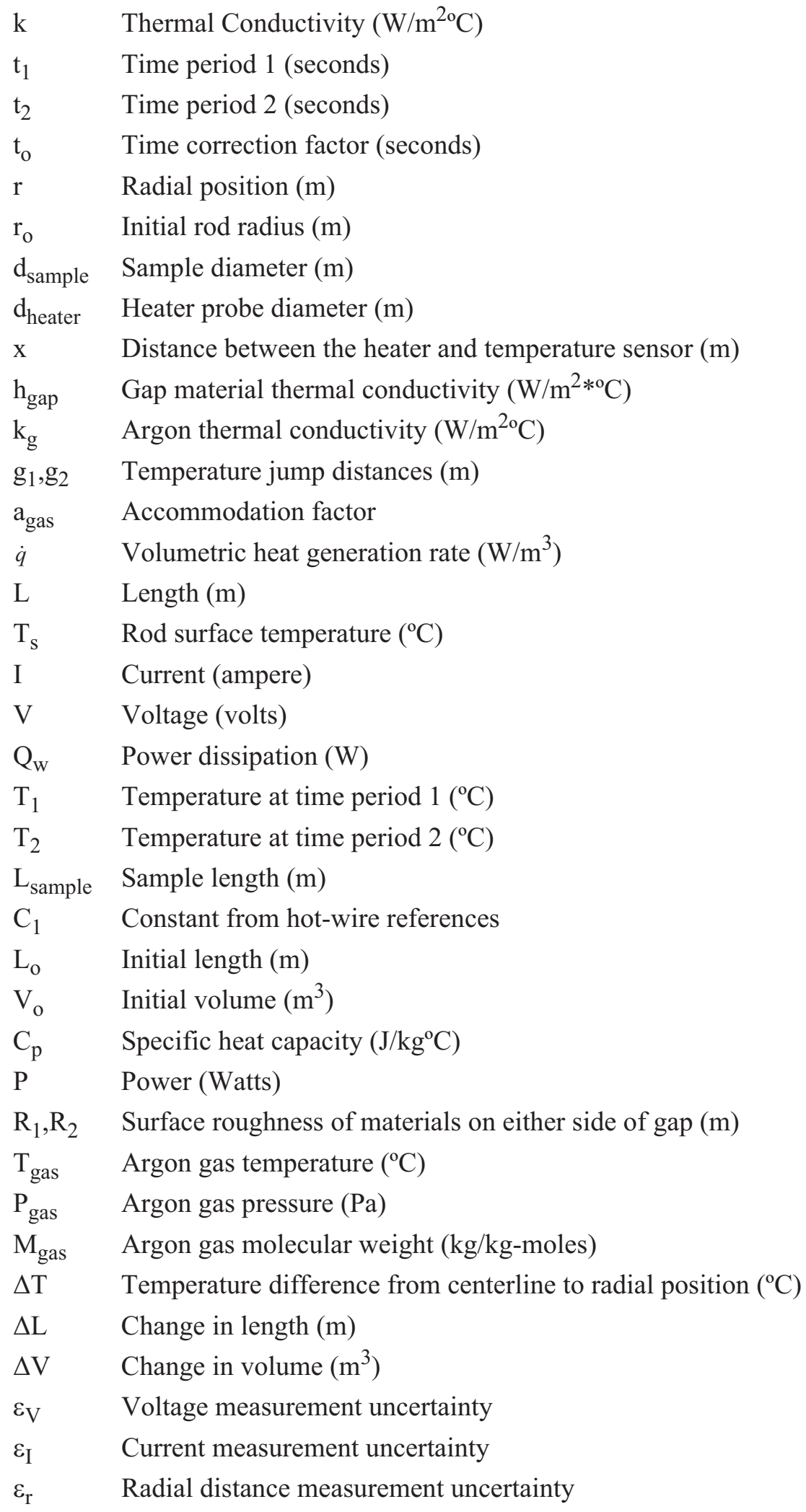




$\begin{array}{ll}\varepsilon_{\Delta \mathrm{T}} & \text { Temperature difference measurement uncertainty } \\ \varepsilon_{r_{o}} & \text { Rod radius measurement uncertainty } \\ \varepsilon_{\mathrm{L}} & \text { Rod length measurement uncertainty } \\ \alpha & \text { Thermal diffusivity }\left(\mathrm{cm}^{2} / \mathrm{seconds}\right) \\ \alpha_{\mathrm{L}} & \text { Linear coefficient of thermal expansion } \\ \rho_{\mathrm{f}} & \text { Final density }\left(\mathrm{kg} / \mathrm{m}^{3}\right) \\ \rho & \text { Density }\left(\mathrm{kg} / \mathrm{m}^{3}\right)\end{array}$




\section{INTRODUCTION}

Thermophysical properties of materials must be known for proper design, test, and application of new fuels and structural properties in nuclear reactors. In the case of nuclear fuels during irradiation, the physical structure and chemical composition change as a function of time and position within the rod. Typically, thermal conductivity changes, as well as other thermophysical properties being evaluated during irradiation in a materials and test reactor, are measured out-of-pile in "hot-cells." Repeatedly removing samples from a test reactor to make out-of-pile measurements is expensive, has the potential to disturb phenomena of interest, and only provide understanding of the sample's end state at the time each measurement is made. There are also limited thermophysical property data for advanced fuels. Such data are needed for the development of next generation reactors and advanced fuels for existing nuclear plants. Having the capacity to effectively and quickly characterize fuels and material properties during irradiation has the potential to improve the fidelity of nuclear fuel data and reduce irradiation testing costs.

\subsection{Research Objectives}

The Idaho National Laboratory (INL), in collaboration with Utah State University (USU), is investigating two candidate in-pile methods for determining fuel conductivity by using a surrogate fuel rod in a laboratory setting.

The first method is a steady state method that utilizes two thermocouples to calculate fuel rod thermal conductivity, one to monitor fuel centerline temperature and another to monitor temperature at a measured radial position within the rod. The method is being tested under several conditions to assess the sensitivity of the measurement. Prior evaluations suggest that this method has successfully been applied by the Institutt for Energiteknikk (IFE) in the Halden Boiling Water Reactor (HBWR) to detect changes in fuel thermal conductivity during irradiation. ${ }^{1}$

The second method is the Transient Hot Wire Method ${ }^{2}$ (THWM), which is an adaptation of the American Standard Test Method (ASTM) hot-wire method. In a solid, this method is applied by embedding a line heater in the material whose thermal conductivity is to be measured. From a condition of equilibrium, the heater is energized and heats the sample with constant power. The thermal conductivity is found from the temperature rise measurement at a small distance from the heater. Preliminary investigations by INL indicate that this approach may offer advantages over two-thermocouple techniques. ${ }^{3}$

INL/USU research objectives are:

1 - Explore the benefits and limitations of the two-thermocouple steady-state and hot-wire transient methods as in-pile thermal conductivity measurement techniques:

2 - Quantify accuracy of techniques by comparisons with standard laboratory material property measurement systems and thermal analysis from the finite element analysis code, ABAQUS, ${ }^{4}$ predictions. 


\subsection{Report Objectives}

This report is the first of a series of reports that document USU/INL testing in this effort. The objective of this series of reports is to document and obtain feedback and suggestions on our progress. It is anticipated that several progress reports will be issued during this project.

\subsection{Report Content}

This report has been organized into five sections. Section 2 gives an introduction to both proposed methods for this project. The introduction of the methods includes explanations of each method with governing equations, limitations, and previous testing experience. Section 2 also identifies the proposed surrogate materials and describes temperature-dependent material property testing required to validate experimental testing. Section 3 explains the setup and method of the two-thermocouple technique, the first method explored in this effort. Section 4 presents all testing results obtained thus far, including CFOAM25 material properties testing, CFOAM25 experimental testing, and CFOAM25 simulated ABAQUS finite element results. Section 5 describes the general conclusions of all testing to date. Ultimately, recommendations for an in-pile sensor for detecting thermal conductivity will be provided in Section 5. References in this report are listed in Section 6. 


\section{PROPOSED METHODS}

Background information, governing equations, and limitations of the two candidate in-pile techniques are found in this section. The surrogate materials are introduced, and specific temperature-dependent properties necessary for experimental testing validation are identified. This section also describes the finite element model developed for the ABAQUS analysis evaluations.

\subsection{Two-Thermocouple Method}

The two-thermocouple method is based on a well known heat transfer phenomenon, ${ }^{5}$ where heat generated within a rod is transferred to the surface. The temperature profile within the rod can be determined by knowing input parameters, such as rod geometry, material properties, and heat generation rate. The twothermocouple method uses two thermocouples embedded in the rod, one at its centerline and another 3/8" from its centerline, to measure two temperatures within the rod while volumetric heat generation is simulated by Joule heating from a measured input power. Knowing two temperatures from different radial locations in the rod, power supplied to the rod, and rod geometry, the thermal conductivity of a material can be calculated.

\subsubsection{Governing Equations}

As shown in Figure 2-1, the method for quantifying the steady state thermal conductivity of a fuel rod, $k$, can be obtained from two-thermocouple technique data:

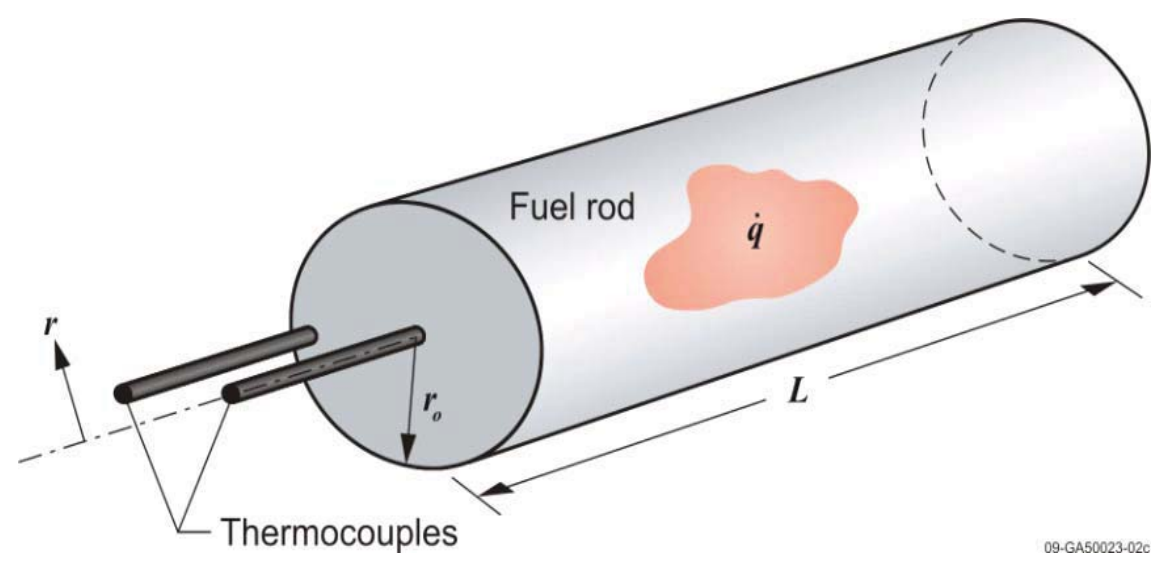

Figure 2-1. Solid cylinder heat conduction with uniform heat generation

where

$$
\begin{aligned}
& \dot{q}-\quad \text { volumetric heat generation rate } \\
& \mathrm{r}-\text { radial position within the rod } \\
& \mathrm{r}_{\mathrm{o}}-\text { radius of the rod } \\
& \mathrm{L}-\text { rod length }
\end{aligned}
$$


Starting with the cylindrical form of the heat conduction equation with constant heat generation rate:

$$
\frac{1}{r} \frac{d}{d r}\left(r \frac{d}{d r}\right)+\frac{\dot{q}}{k}=0
$$

Applying a zero temperature gradient at the rod centerline and assuming a surface conduction/convection balance boundary condition, the above equation can be integrated to find the temperature distribution in the rod as a function of radial position:

$$
T(r)=\frac{\dot{q} r_{o}^{2}}{4 k}\left(1-\frac{r^{2}}{r_{o}^{2}}\right)+T_{s} .
$$

Equation (2-2) can be used to define an equation for the temperature at the fuel rod centerline, $\mathrm{T}(0)$ :

$$
T(0)=\frac{\dot{q} r_{o}^{2}}{4 k}+T_{s}
$$

Defining the temperature difference between the centerline and the radial position, $\Delta T=T(0)-T(r)$. Equations (2-2) and (2-3) can be combined to obtain the following relationship for thermal conductivity:

$$
k(r)=\frac{\dot{q} r^{2}}{4 \Delta T}
$$

Hence, thermal conductivity can be calculated if the radial position from the sample centerline, $r$; volumetric heat generation rate, $\dot{q}$; and measured temperature difference, $\Delta T$, are precisely known.

\subsubsection{Method Limitations and Uncertainty}

There are acknowledged limitations to the two-thermocouple method. Placing two thermocouples within a prototypic-sized 1/2" diameter fuel rod will incur significant perturbations in the measured fuel thermal conductivity. Another limitation of the method, which is inherent to measuring temperature using thermocouples, is the contact resistance between the thermocouples and sample. Since the method uses two thermocouples, the error from this source is essentially doubled. As a first effort, the approach in Reference 6 was applied to estimate the uncertainty in the experimental measurements (even though the approach and setup uncertainties are not included within this analysis of uncertainty). Equation (2-4) is rearranged to evaluate the uncertainty impact of each measurement parameter:

$$
k=\frac{I V r^{2}}{4 \pi L r_{o}^{2} \Delta T}
$$

where $\dot{q}$ is defined as the product of measured current, $I$, and measured voltage, $V$, divided by the volume, with $r_{o}$ being the radius of the rod and $L$ the length of the rod. Defining $d k$ as the uncertainty of Equation (2-4), the partial differentials can be taken of Equation (2-5):

$$
d k=\frac{V r^{2}}{4 \pi \Delta T r_{o}^{2} L} d I+\frac{I r^{2}}{4 \pi \Delta T r_{o}^{2} L} d V+\frac{2 I V r}{4 \pi \Delta T r_{o}^{2} L} d r-\frac{I V r^{2}}{4 \pi(\Delta T)^{2} r_{o}^{2} L} d \Delta T-\frac{I V r^{2}}{2 \pi \Delta r_{o}^{3} L} d r_{o}-\frac{I V r^{2}}{4 \pi \Delta T r_{o}^{2} L^{2}} d L
$$


Dividing by $k$ :

$$
\frac{d k}{k}=\frac{d V}{V}+\frac{d I}{I}+2\left(\frac{d r}{r}-\frac{d r_{o}}{r_{o}}\right)-\frac{d \Delta T}{\Delta T}-\frac{d L}{L},
$$

Using uncertainty terminology from Reference 6, where:

$$
\varepsilon_{k}=\frac{d k}{k}, \varepsilon_{V}=\frac{d V}{V}, \varepsilon_{I}=\frac{d I}{I}, \ldots, \varepsilon_{L}=\frac{d L}{L}
$$

thus, a first approximation for the general uncertainty of the two-thermocouple experimental method is:

$$
\varepsilon_{k}=\sqrt{\left(\varepsilon_{V}\right)^{2}+\left(\varepsilon_{I}\right)^{2}+2\left(\varepsilon_{r}\right)^{2}+2\left(\varepsilon_{r_{o}}\right)^{2}+\left(\varepsilon_{\Delta T}\right)^{2}+\left(\varepsilon_{L}\right)^{2}} .
$$

In the above equation, $\varepsilon_{V}$ is the voltage measurement uncertainty provided by the power supply manufacturer, $\varepsilon_{I}$ is the current measurement uncertainty based on calibration numbers, $\varepsilon_{r}$ is the uncertainty from radial distance measurement based on thermocouple dimensions and machining tolerances, $\varepsilon_{\Delta T}$ is the uncertainty from the $\Delta \mathrm{T}$ measurement given by the thermocouple manufacturer, $\varepsilon_{r_{o}}$ is the uncertainty from the radius measurement, and $\varepsilon_{L}$ is the length measurement uncertainty. Table 2.1 shows the percentage of contributing uncertainty from each of these sources.

Table 2.1. Two-thermocouple method contributing error

\begin{tabular}{|c|c|}
\hline Error Source & Error Percentage \\
\hline$\varepsilon_{V}$ & 2.10 \\
\hline$\varepsilon_{I}$ & 0.10 \\
\hline$\varepsilon_{r}$ & 8.36 \\
\hline$\varepsilon_{\Delta T}$ & 0.75 \\
\hline$\varepsilon_{r_{o}}$ & 0.10 \\
\hline$\varepsilon_{L}$ & $9.30 \mathrm{E}-2$ \\
\hline$\varepsilon_{k}$ & 12.03 \\
\hline
\end{tabular}

Table 2.1 indicates that the largest calculated uncertainty is from the placement of the thermocouples within the sample and measuring the exact location. The assumption of measuring temperature at a finite point within the material of the rod is used with this method. This assumption does not include the thermocouples having a different material than the surrogate rod material; therefore, the larger the diameter ther- 
mocouple, the more error will be introduced. Also, there can be a considerable error contribution by gap resistance between the thermocouple and the sample. While not discussed in this report, improvements to experimental measurements from gap resistance will be assessed by this project at a later date.

\subsubsection{Halden Experience for In-Pile Application}

The IFE at the Haldenprosjektet (HRP) has successfully applied the two thermocouple approach for detecting fuel rod conductivity degradation during irradiation. ${ }^{7}$ The approach relies on data from a thermocouple in the fuel rod to give centerline temperature and a second thermocouple placed on the exterior of the fuel cladding. Fuel thermal conductivity was calculated to obtain the plot shown in Figure 2-2.

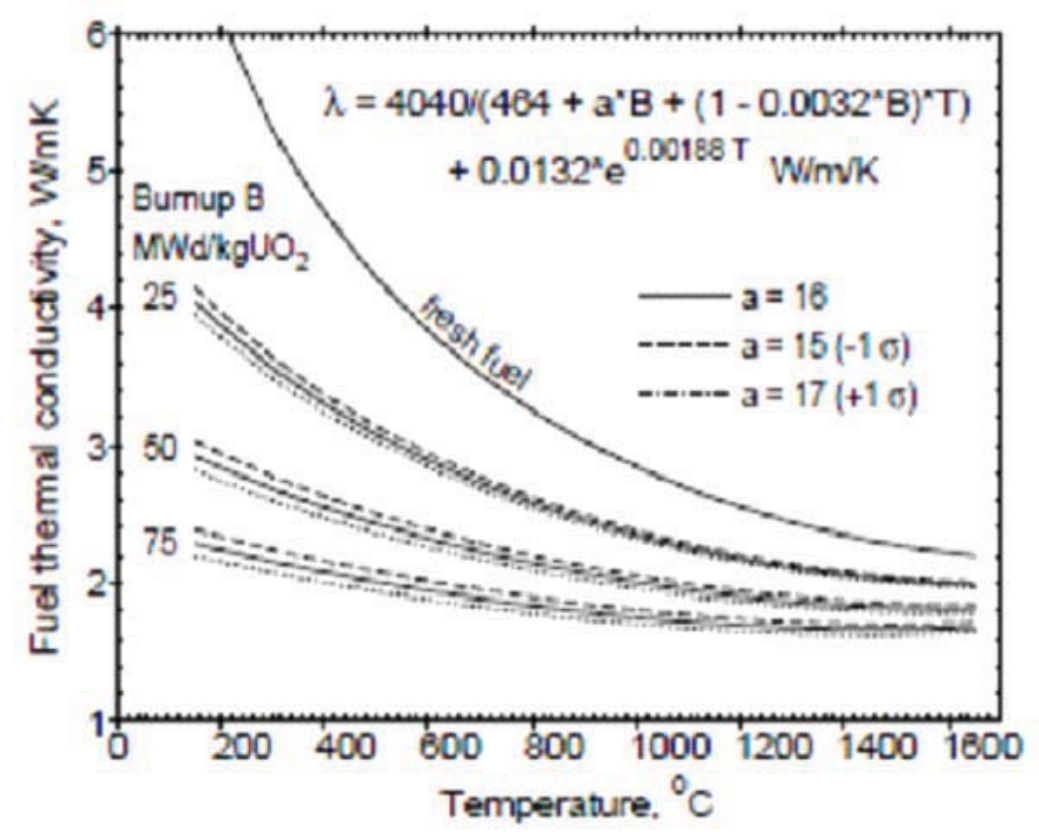

Figure 2-2. Halden generated plot of fuel thermal conductivity as a function of rod burn-up ${ }^{8}$

Although not explicitly stated in References 1, 7, and 8, it appears that IFE-HRP must invoke several assumptions to apply this technique. For example, this approach requires assumptions, such as uniform fuel composition, uniform fuel density, estimating gap conductances by monitoring fission gas releases and gap closure ${ }^{1}$, and known heat generation distribution of the fuel rod.

\subsection{Transient Hot Wire Method}

The Transient Hot Wire Method (THWM) or line heat source method, was first suggested by Schleirmacher. ${ }^{9}$ Numerous references may be found in the literature describing applications of this method to measure the thermal conductivity of solids, fluids, and gases (e.g., see References 10 through 15). Today, several commercial vendors offer systems measuring thermal conductivity based on THWM techniques (e.g., see Reference 10). 


\subsubsection{Governing Equations}

In a solid, this method may be applied by embedding a line heat source in the material whose thermal conductivity is to be measured. From a condition of equilibrium, the heat source is energized and heats the sample with constant power. The temperature response of the sample is a function of its thermal properties. The thermal conductivity is found from the temperature rise at a small distance from the heat source. Following a brief transient period, a plot of the temperature versus the natural logarithm of time becomes linear, as shown in Figure 2-3 (the time period between $t_{1}$ and $t_{2}$ ). The thermal conductivity for the sample can be calculated from the following relation: ${ }^{11,15}$

$$
k=\frac{Q_{w} \ln \left(\frac{t_{2}-t_{o}}{t_{1}-t_{o}}\right)}{4 \pi\left(T_{2}-T_{1}\right)},
$$

where the power dissipation by the heater wire, $Q_{w}$, is related to the thermocouple temperature at the time when the linear portion of the curve started, $T_{1}$, and the temperature when the linear portion of the response curve ended, $T_{2}$. Some references include a time correction factor, $t_{0}$, which is calculated from the data to account for the finite size of the heater and differences in properties between the sample, line heater, and thermocouple.

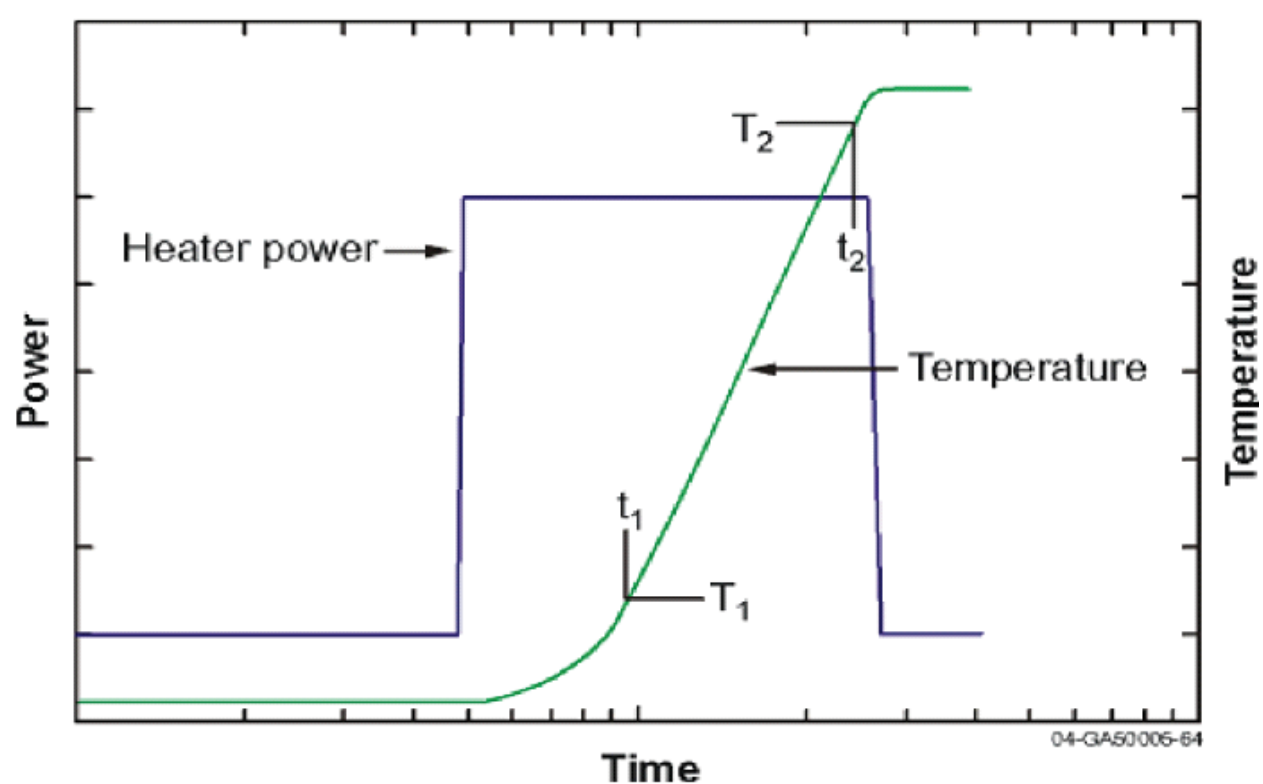

Figure 2-3. Typical time versus temperature plot for hot wire method

One source of error with this method is associated with the finite length of the heater. In Reference 15, it is noted that investigators have recommended minimum values for the heater length to diameter ratios that range from 31 to 100 . For accuracies of $1 \%$, Reference 13 recommends that the ratio of the sample diameter, $d_{\text {sample }}$, to heater probe diameter, $d_{\text {heater }}$, be at least 60 and that the length of the sample, $L_{\text {sample }}$, be selected based on its thermal diffusivity and estimated test period, $t_{2}$, using the following relationship:

$$
L_{\text {sample }} \geq 7.96\left(\alpha t_{2}\right)^{0.5} \text {. }
$$




\subsubsection{Method Limitations and Uncertainties}

To enhance the accuracy of this method, several references provide guidance related to sample material (based on its thermal diffusivity, $\alpha$ ) the distance of the heater from the temperature sensor, $x$, the sample diameter, $d_{\text {sample }}$, the relationship between $t_{1}$ and $t_{2}$, and the thermal contact between the sample and the heater and sample and the sensor. With respect to the distance between the heater and the temperature sensor, Reference 14 recommends that the following relation be applied:

$$
t_{1} \gg \frac{x^{2}}{\alpha}
$$

With respect to the sample diameter, several references recommend that the following relationship be considered.

$$
t_{2}<C_{1}\left(\frac{d_{\text {sample }}^{2}}{4 \alpha}\right)
$$

with $C_{1}$ varying from 0.1 (Reference 14 ) to 0.15 (Reference 13) for accuracies of $1 \%$. The accuracy of the measured thermal conductivity is enhanced if the ratio of $t_{2} / t_{1}$ is increased. Reference 14 suggests that $t_{2}$ should be greater than 800 seconds. To increase this accuracy, the experimentalist can vary the heater power level applied to a particular material. Finally, it is desirable to have good thermal contact between the probe and the sample material and the temperature sensor and the sample material. Poor contact will delay the time at which the thermal response will become linear and the time when the thermal response ceases to be linear. Correction factors or experimental techniques may need to be imposed to account for imperfect thermal contact.

\subsubsection{INL Experience}

Preliminary investigations ${ }^{3}$ at INL's High Temperature Test Laboratory (HTTL) suggest that the THWM would be a viable technique for measuring thermal conductivity of materials during irradiations in INL's Advanced Test Reactor (ATR). Advantages of this method are its potential to yield data with shorter measurement times (than possible with steady state methods) and because of its ease of installation for an in-pile sensor (compared to other transient methods such as transient pulsed diffusivity methods used in specialized laboratory systems). INL has explored the THWM using two sample configurations in a laboratory setting. However, initial attempts suffered from measurement inaccuracies due to the selected sample, sensor, and heater geometries and thermocouple/heater-to-sample gap contact resistances. Lessons learned from these initial INL attempts will be incorporated into the current INL/USU program.

\subsection{Surrogate Rod Materials}

Surrogate materials provide an inexpensive yet efficient view of the proposed methods' limitations and advantages. The criteria for selecting surrogate materials were based on how material properties would affect laboratory measurement ranges. For example, electrical resistivity of a material determines how well current can flow through the material; but the lower the resistivity of a material, the larger the supplied current needs to be to generate sufficient volumetric heat generation by Joule heating. Spreadsheets were cre- 
ated with upper and lower measurement limits of current, voltage, electrical resistance, thermal conductivity, sample geometry, and sample temperature difference. From these spreadsheets, a limiting range was calculated for selecting possible materials. Machinability and maximum service temperature were some of the other important selection criteria. The first surrogate material selected for evaluation in this project is $\mathrm{CFOAM}^{\circledR}$.

\subsubsection{CFOAM}

The initial surrogate fuel rod material chosen for this proof-of-concept test is CFOAM $^{\circledR}$. This carbon structural foam is non-combustible and will not off-gas at high temperatures. CFOAM ${ }^{\circledR}$ is calcined coke (CAS \#64743-05-1) ${ }^{17}$ engineered to meet high performance material needs. It has a high tolerance to impact damage and can be integrated with other materials, such as metals or polymer composites.

Table 2.2 from Reference 17 summarizes properties provided by Touchtone Research Laboratories Ltd., the manufacturer of this material. Although these data were useful for preliminary selection of $\mathrm{CFOAM}^{\circledR}$, more detailed, temperature-dependent, material property data are needed for the USU/INL evaluations in this project.

Table 2.2. CFOAM vendor supplied properties data ${ }^{17}$

\begin{tabular}{|c|c|c|c|c|}
\hline Property & Test Method & CFOAM20 & CFOAM25 & Unit \\
\hline \multirow{2}{*}{ Nominal Density } & \multirow{2}{*}{ ASTM D1622 } & 20 & 25 & $\mathrm{lbs} / \mathrm{ft}^{3}$ \\
\hline & & 0.32 & 0.4 & $\mathrm{~g} / \mathrm{cm}^{3}$ \\
\hline \multirow{2}{*}{ Thermal Conductivity ${ }^{\mathrm{a}}$} & \multirow[t]{2}{*}{ ASTM E 1225} & \multicolumn{2}{|c|}{0.15 to 16} & $\mathrm{BTU} / \mathrm{ft}-\mathrm{hr}^{\circ} \mathrm{F}$ \\
\hline & & \multicolumn{2}{|c|}{0.25 to 25} & $\mathrm{~W} / \mathrm{mK}$ \\
\hline \multirow{2}{*}{$\begin{array}{c}\text { Maximum Operational Use } \\
\text { Temperature }\end{array}$} & & \multicolumn{2}{|c|}{1100 Air } & ${ }^{\circ} \mathrm{F}$ \\
\hline & & \multicolumn{2}{|c|}{600 Air } & ${ }^{\circ} \mathrm{C}$ \\
\hline \multirow{2}{*}{ Electrical Resistivity ${ }^{\mathrm{a}}$} & \multirow[t]{2}{*}{ ASTM D 4496} & \multicolumn{2}{|c|}{$4 \mathrm{E}-03$ to $\mathrm{E}+06$} & Ohm-in \\
\hline & & \multicolumn{2}{|c|}{$1 \mathrm{E}-02$ to $1 \mathrm{E}+07$} & Ohm-cm \\
\hline
\end{tabular}

a. Can be tailored for specific applications.

Although two CFOAM ${ }^{\circledR}$ materials (CFOAM20 and CFOAM25) were initially considered, the denser CFOAM25 was found to have more desirable properties for this application.

\subsubsection{Material 2}

Testing with material 2 has yet to begin at INL's High Test Temperature Laboratory (HTTL). However, details of material selection and results will be provided in the next progress report. 


\subsection{Material Property Testing Measurements}

As discussed within this section, initial room temperature material property data for these materials suggested that they would be suitable for testing in a laboratory setting. However, in order to properly validate proposed methods for estimating thermal conductivity, temperature-dependent properties of surrogate fuel rods must be quantified. Three important property measurements were made to estimate the material's thermal conductivity because thermal conductivity of a material can be defined as the product of density, specific heat, and thermal diffusivity. These values were measured using specialized laboratory systems located at INL's HTTL.

\subsubsection{Density}

The density of a material as a function of temperature was calculated using data obtained from a pushrod dilatometer. This machine measures thermal elongation of a material with respect to temperature. Recalling that density is fundamentally defined as mass per volume, the linear coefficient of thermal expansion is defined as the differential change in length per change in temperature:

$$
\alpha_{L}=\frac{1}{L_{o}} \frac{\partial L}{\partial T}
$$

where $L_{o}$ is the initial length. The above expression is often rewritten as:

$$
\frac{\Delta L}{L}=\alpha_{L} \Delta T
$$

where $\Delta L$ is the sample change in length, $\alpha_{L}$ is the coefficient of linear expansion, and $\Delta T$ is the sample change in temperature. For isotropic materials, the volumetric coefficient of expansion is very closely approximated as three times the linear coefficient of thermal expansion:

$$
\frac{\Delta V}{V_{o}}=3 \alpha_{L} \Delta T
$$

where $\Delta V$ is the sample volume change, and $V_{o}$ is the initial volume. The final volume is defined as initial volume plus the change in volume. These relationships can be combined to obtain the final density, defined as a function of sample mass, initial sample volume and length, and change in sample length, as shown by Equation 2-17:

\subsubsection{Thermal Diffusivity}

$$
\rho_{f}=\frac{\operatorname{mass}}{V_{o}\left(1+3 \frac{\Delta L}{L_{o}}\right)} .
$$

Thermal diffusivity, $\alpha$, is defined as the material's thermal conductivity divided by the product of the material's density and specific heat. Hence, thermal diffusivity effectively relates a material's ability to conduct energy to its ability to store energy. ${ }^{18}$ Thermal diffusivity was measured at INL's HTTL using a 
laser flash thermal diffusivity system. The system provides high energy pulse heating to one surface of a sample; the imposed thermal transient allows measurements of how well heat transfers through the sample, which is then used to estimate the material's thermal diffusivity.

\subsubsection{Specific Heat Capacity}

Specific heat capacity measurements were conducted at INL's HTTL using a Differential Scanning Calorimeter (DSC). A complete DSC test requires three individual tests: a baseline test without any sample material (results from this test are used to eliminate any bias from test to test variations), a test containing a reference sample with well known $C_{p}$ values in order to calculate the unknown sample $C_{p}$ values, and a test with sample whose properties are unknown. Precision is required for accurately characterizing the specific heat using this test, and one of the more important requirements is closely matching the masses of the test sample to the reference sample.

\subsubsection{Thermal Conductivity}

Once the above measurements were made for each surrogate material, its temperature-dependent thermal conductivity from material property values was estimated using Equation 2-18:

$$
k=\alpha \rho C_{p}
$$

\subsection{Finite Element Modeling Using ABAQUS}

ABAQUS is a Finite Element Analysis (FEA) tool which has numerous capabilities and advantages over many FEA packages. The mesh developed for the two thermocouple analysis is detailed in this section. The ABAQUS model was developed to provide insights and comparisons regarding the experimental results. Also the model was used to help bound the potential effects of non-ideal contact thermal resistance.

\subsubsection{Model Development}

The software package ABAQUS was used to generate a 3-D model of the experimental setup used to measure the steady state thermal conductivity of a fuel rod surrogate. Key features of the model include representations of the surrogate fuel rod, type-K thermocouples, and gap elements used to evaluate the effects of conduction contact resistance.

Section 4 surrogate fuel rod material property data, were used to define the model thermal parameters as a function of temperature. The model was constructed as a single extruded three-dimensional deformable part, with separate components (surrogate rod material, thermocouples, and gaps) defined by partitions. Separate components were assigned materials with properties either defined through testing or reference data. The thermocouples were modeled using weighted average material properties. These properties were derived by averaging the properties of each component, with the contribution of each component weighted by its fraction of the total cross-sectional area of the thermocouple at a point near the junction. Thermoelements were considered to be composed of Chromel and Alumel. Insulation was considered to be alumina. Thermocouple sheaths were assumed to be Inconel 600 . The gap elements were 
modeled as solids in order to simplify the model. The assembled model structure is shown in Figure 2-4; and a close up view of the intersection of the fuel surface, the thermocouples, and the gap elements is shown in Figure 2-5.

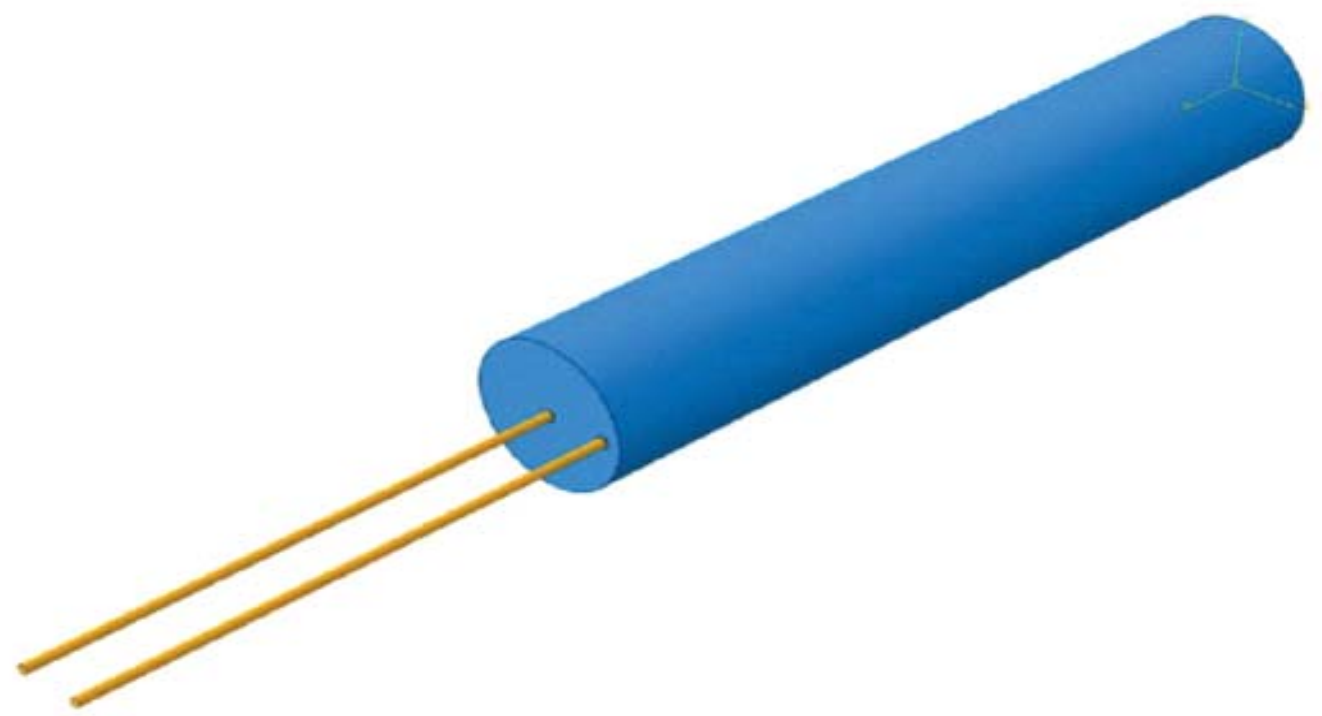

Figure 2-4. Model assembly

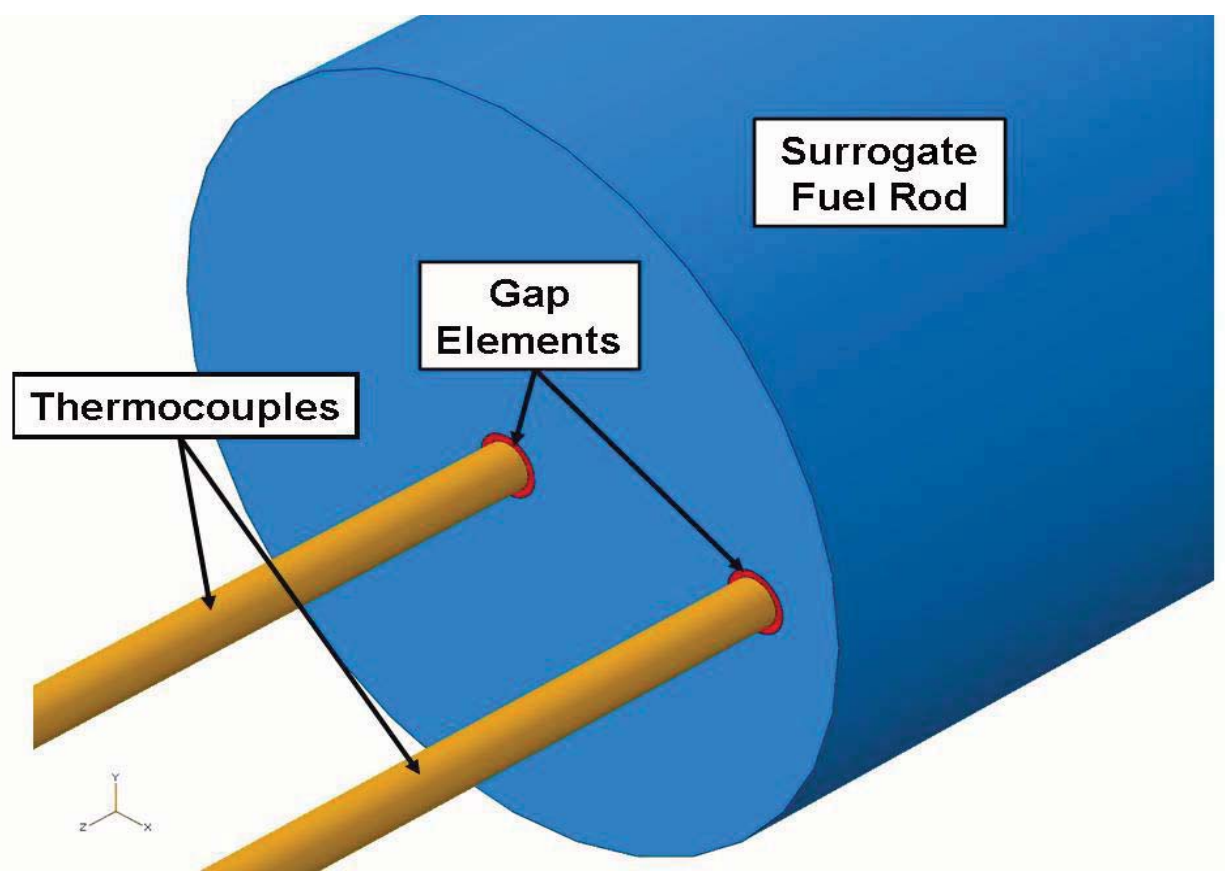

Figure 2-5. Close up view of model components 
The gap material was given values for density and specific heat capacity that match the properties of argon, the gas in which the test was conducted. Thermal conductivity of the gap material was derived using Equation 2-19: ${ }^{19}$

$$
h_{g a p}=\frac{k_{g}}{3.6\left(R_{1}+R_{2}\right)+\left(g_{1}+g_{2}\right)} \text {, }
$$

where:

$$
\begin{array}{ll}
k_{g} \quad- & \text { thermal conductivity of } \operatorname{argon}\left(\mathrm{W} / \mathrm{m}^{2 \mathrm{o}} \mathrm{C}\right) \\
R_{1}, R_{2}- & \text { surface roughness of materials on each side of the gap }(\mathrm{m}) \\
g_{1}, g_{2}- & \text { temperature jump distances }(\mathrm{m})
\end{array}
$$

and

$$
g_{1}+g_{2}=\frac{0.0247 k_{g} T_{\text {gas }}^{0.5}}{P_{\text {gas }} \frac{a_{\text {gas }}}{M_{\text {gas }}}}
$$

where:

$$
\begin{aligned}
& T_{\text {gas }}-\text { temperature of the argon }(\mathrm{K}), \text { taken as furnace temperature } \\
& P_{\text {gas }}-\text { pressure of the argon }(\mathrm{Pa}), \text { taken as atmospheric } \\
& M_{\text {gas }}-\text { molecular weight of argon }(\mathrm{kg} / \mathrm{kg} * \text { moles }) \\
& a_{\text {gas }}-\text { accommodation factor }{ }^{20} \text { ranging between } 0 \text { and } 2
\end{aligned}
$$

The thermal conductivity of the gap elements was then by defined as $h_{\text {gap }}$ multiplied by the thickness of the element. The extremes of measured values for each surrogate rod gap conductivity, along with the average values, were provided to the surrogate rods.

ABAQUS allows direct application of volumetric heat loads. Volumetric heat generation of the surrogate fuel elements was approximated in the experiment using the electrical resistance heating of the fuel.

The final physical condition to be modeled was surface cooling of the fuel and the thermocouples. Due to the complexity of estimating both convective and radiation cooling coefficients as functions of temperature, experimental data were used. The film cooling coefficient was adjusted such that the peak model temperature registered by the centerline thermocouple matched closely that given in the experiment.

The ABAQUS software allows for automatic mesh generation. Due to the small dimensions of the gap elements, a global seed size of $2.2 \mathrm{~mm}$ was chosen. The mesh was then automatically generated. The meshed assembly is shown in Figure 2-6. It should be noted that the mesh of the gap elements and of the thermocouple sections that are within the fuel are suppressed from display by the ABAQUS program, as these meshes are very dense. 


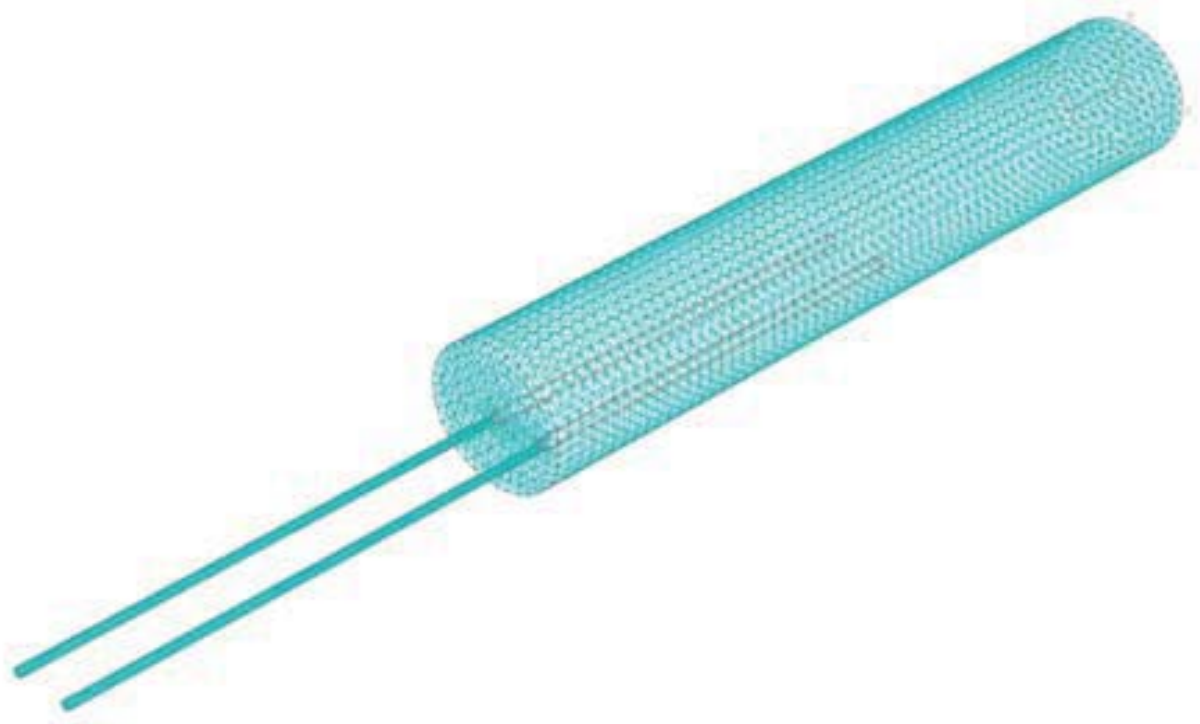

Figure 2-6. ABAQUS generated mesh

The test data were obtained using two input power levels, total power dissipations of 40 and 100 watts. As such, the model was set up with two steps, one accommodating each power level. The model was run as a transient analysis, with the end condition determined as steady state (defined as a temperature change of less than $0.001{ }^{\circ} \mathrm{C}$ between iterations). A typical visualization of the steady state surface temperature condition is shown in Figure 2-7.

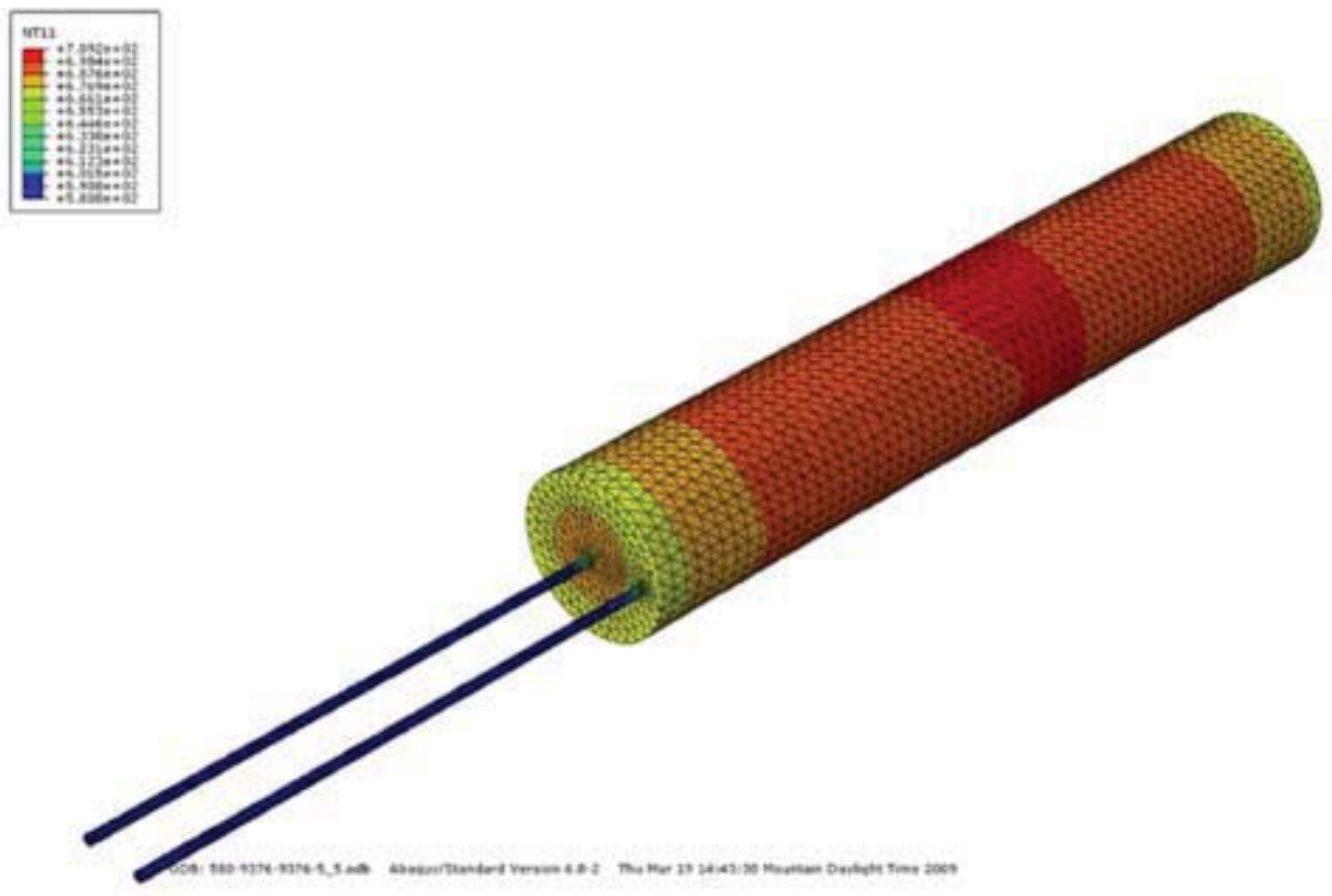

Figure 2-7. Steady state surface temperature distribution 
A cutaway view of the model is shown in Figure 2-8. Two nodes (highlighted in the figure) were chosen to simulate the thermocouple junctions. The temperatures recorded at these nodes were used for determining $\Delta T$ and effective thermal conductivity.

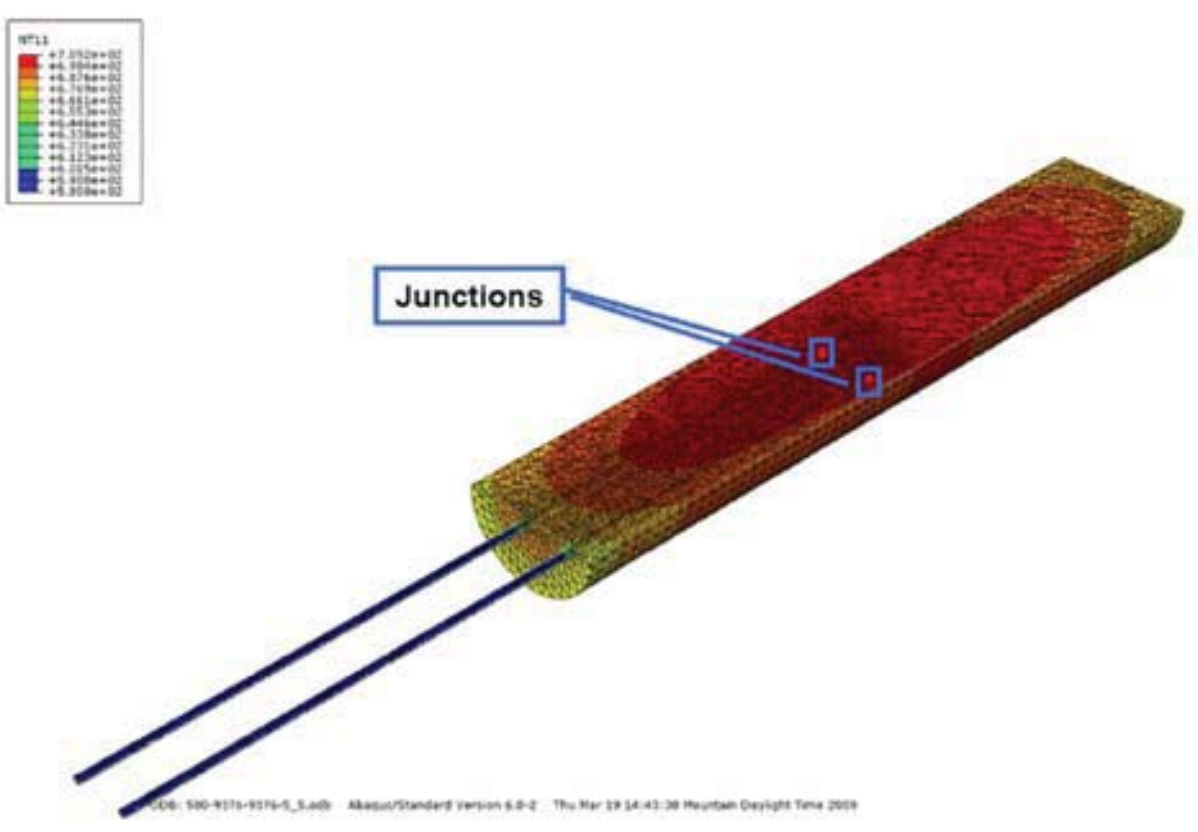

Figure 2-8. Cutaway model view with thermocouple junctions highlighted

Figure 2-9 shows a representative ABAQUS generated test result for power levels at 40 watts and 100 watts. The curves shown in Figure 2-9 are the temperatures of each junction node with respect to time. As seen in the figure, the $\Delta T$ during the initial transient is much less than at steady state. This effect was noticed also during experimental testing. Also noticed in Figure 2-9 is the larger $\Delta T$ and higher steady state temperature point for $100 \mathrm{~W}$ than $40 \mathrm{~W}$. These two effects were also noticed in experimental testing. 


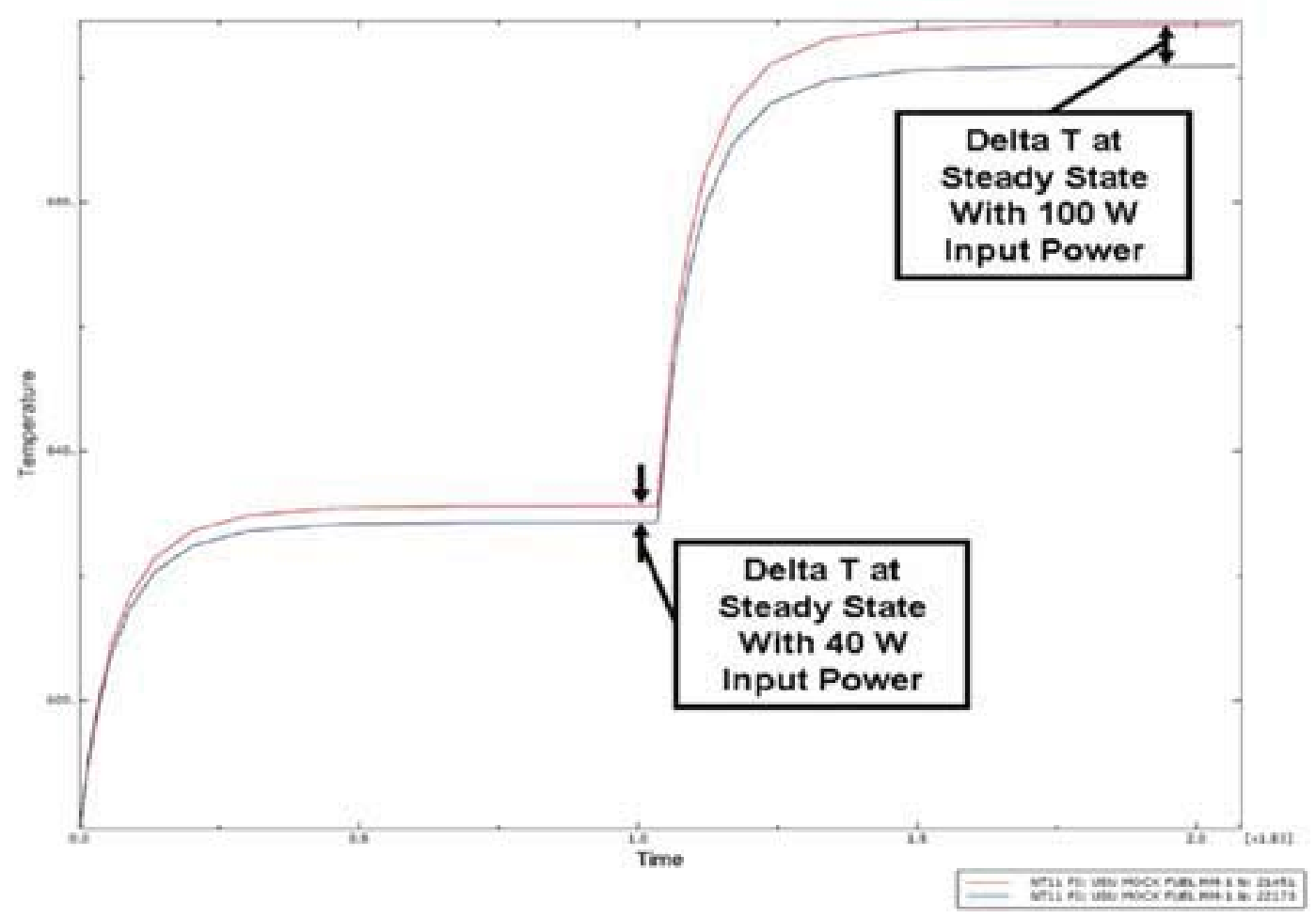

Figure 2-9. Representative transient ABAQUS output

\subsubsection{Proposed ABAQUS Test Cases}

Parameters defining the model will be varied in a similar manner as those varied in the experimental setup. Table 2.3 shows proposed variations for the two thermocouple test setup.

Table 2.3. Proposed testing variations for two-thermocouple model

\begin{tabular}{|c|c|}
\hline Sensitivity & Model Parameter Varied \\
\hline Fuel thermal conductivity & Vary test properties \\
Ambient temperature variation & Vary initial model and sink temperatures \\
Fuel temperature gradient & Vary applied volumetric heat load \\
External cooling conditions & Vary surface film cooling coefficient \\
Contact conductance & Vary thermal conductivity of gap elements \\
Multiple component material & Partition fuel cell and very properties \\
Interior cracking & Add "crack" elements to fuel component \\
\hline
\end{tabular}




\section{SETUP AND METHOD}

Two-thermocouple setup and method details are provided in this section. All testing is performed at INL's HTTL. The hot wire method and setup will be given in the next progress report.

\subsection{Two-Thermocouple Setup}

From the definition of thermal conductivity found in Equation (2.4), the required measured parameters are: outer thermocouple distance from centerline, $r$; volumetric heat generation, $\dot{q}$; and measured temperature difference, $\Delta T$. The test setup shown in Figures 3-1 and 3-2 is being used to obtain data for these parameters.

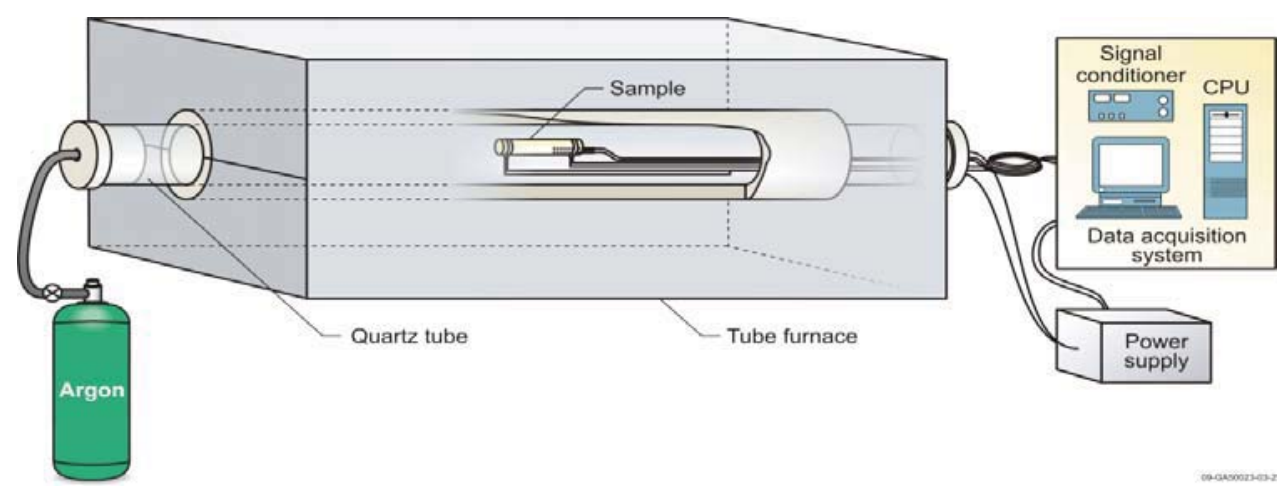

Figure 3-1. Theoretical test setup inside tube furnace

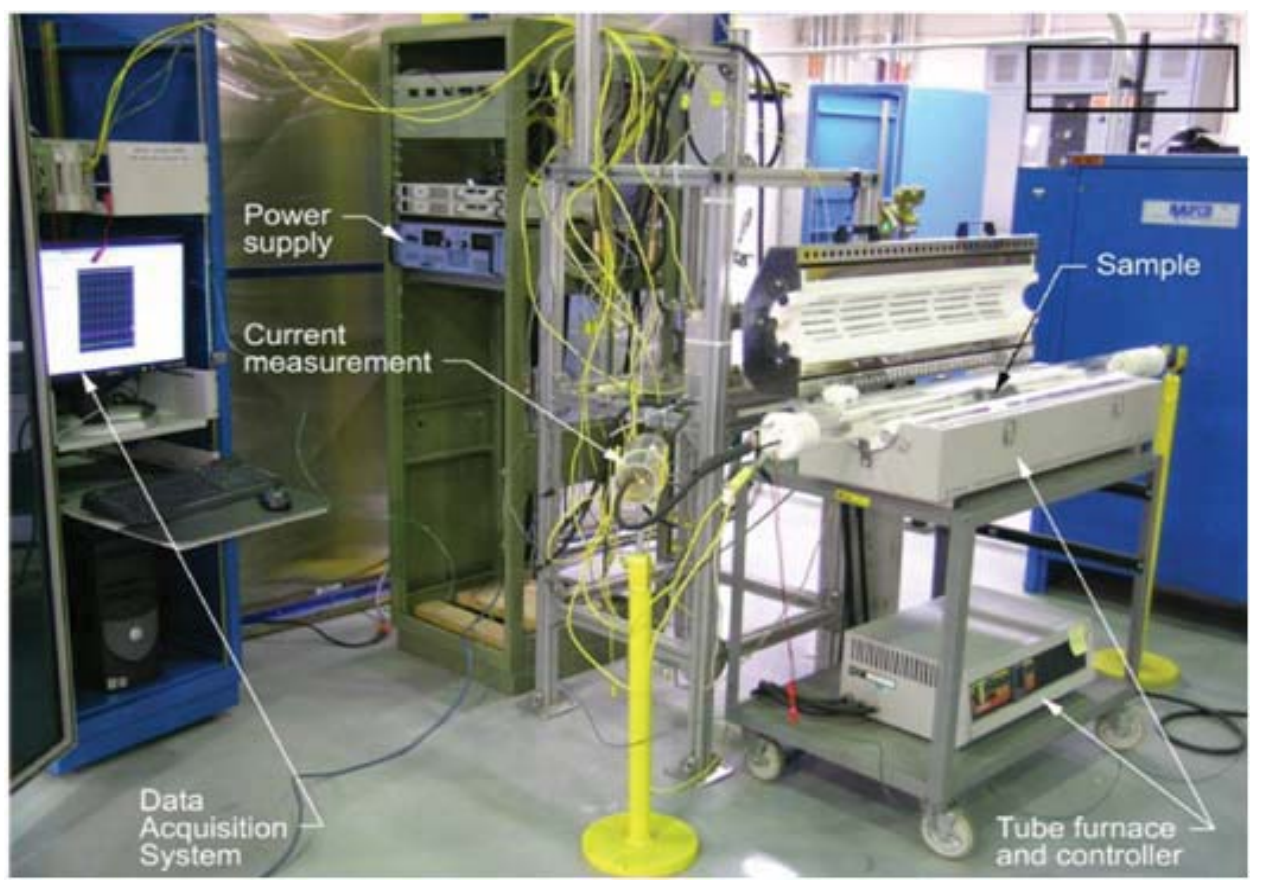

Figure 3-2. Test setup at INL's HTTL 
The samples are positioned inside a tube furnace to control temperature and provide a sample temperature test range from 300 to $800^{\circ} \mathrm{C}$. The tube furnace only changes ambient temperature. A specified voltage and current are supplied to the sample by attaching the power supply to each end of the sample using Inconel electrodes connected to Inconel clamps. Leads attached to Inconel clamps at each end of the surrogate rod measure the voltage drop of the sample. A precision current measurement, commonly called a shunt, measures current within the experimental test loop. Voltage leads are attached to the shunt to measure the voltage drop. Because the shunt resistance is very well known or calibrated, current can be calculated from Ohm's Law. Volumetric heat generation is calculated using the measured current, I; and the sample voltage drop, $V$; sample dimensions, and the relationship between Power, $P$, current, and voltage (e.g., $P=I^{*} V$ ). Flow rates can be adjusted using valves to vary fluid conditions within the tube. The fluid inside the tube can either be air or an inert gas, such as argon. Signals are processed by a data acquisition system to give temperatures from thermocouples and power in the sample. The thermocouples are carefully positioned at known locations within the sample as seen in Figure 3-3.

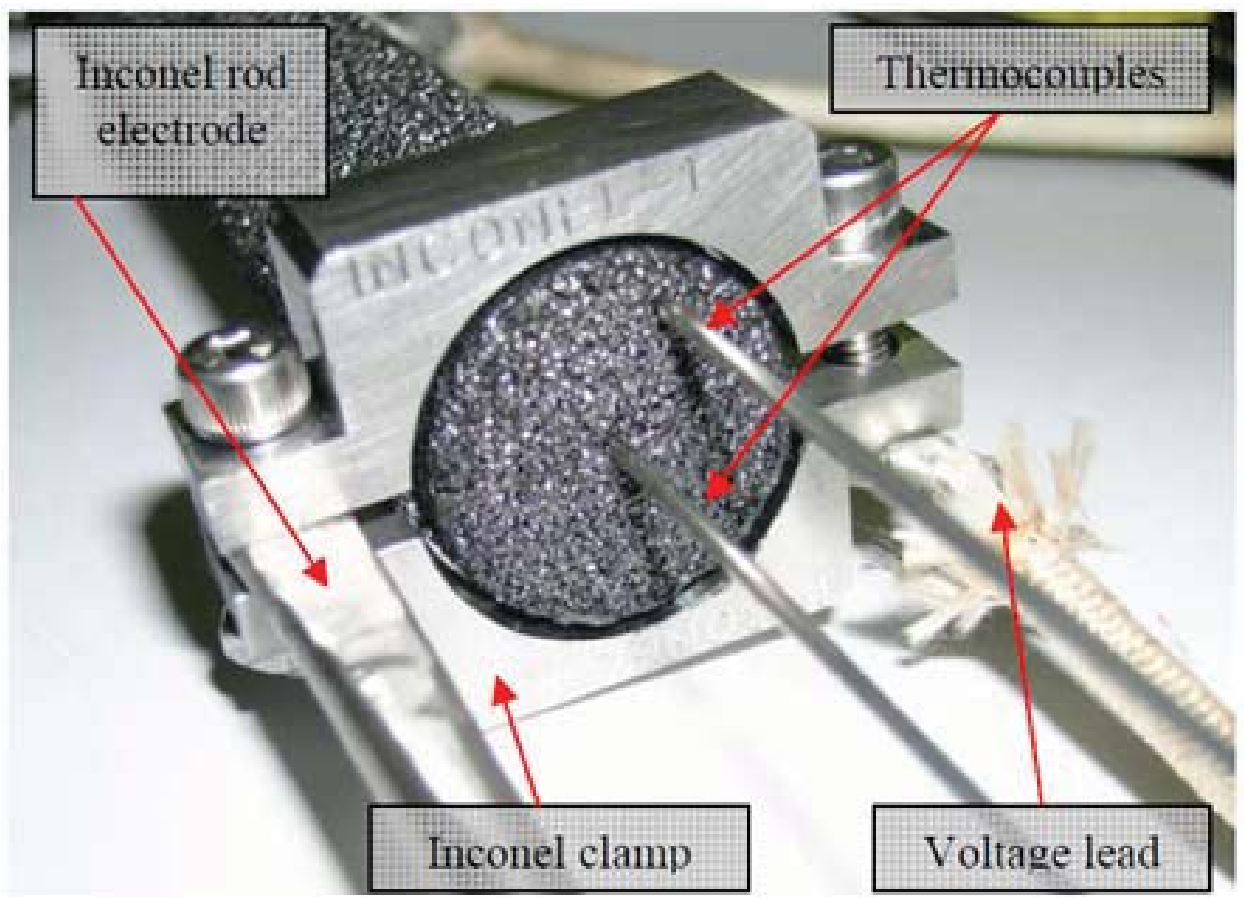

Figure 3-3. $\mathrm{CFOAM}^{\circledR}$ sample with thermocouples inserted 


\subsubsection{Two-Thermocouple Method Sensitivity Testing}

In these INL/USU evaluations, several test parameters will be varied to estimate the accuracy of the proposed method. Table 3.1 shows proposed variations for steady state conditions.

Table 3.1. Proposed testing variations for steady state conditions

\begin{tabular}{|c|c|}
\hline Sensitivity & Experimental Parameter Varied \\
\hline Surrogate rod thermal conductivity & Vary test material \\
\hline Variation in temperature & Vary furnace temperature $\left(200-800{ }^{\circ} \mathrm{C}\right)$ \\
\hline Variation in temperature gradient & Vary power supply parameters \\
\hline Variation in outer boundary condition & Vary gas flow along outer surface of sample \\
\hline $\begin{array}{c}\text { Improved thermocouple to surrogate rod contact } \\
\text { resistance }\end{array}$ & Add graphite powders or lubricant \\
\hline Multiple component material & Sample with various test materials \\
\hline Two region sample with interior cracked & Specialized fabrication \\
\hline
\end{tabular}

Generating results based on the test matrix shown in Table 3.1 consists of selecting variables to hold constant, such as power and exterior flow conditions, and measuring values over the defined temperature range. For example, testing has been conducted by holding supplied power at 100 watts (W) and waiting for sample and furnace to reach steady state equilibrium while holding exterior flow within the tube constant. Once equilibrium is reached, the thermocouple readings do not change with respect to time; and data are recorded. For the next data point, the ambient temperature is increased by increasing the tube furnace temperature and steady state can be reached again. This process is repeated in order to generate data tables for each testing parameter.

\subsection{Transient Hot Wire Setup}

Details of the hot wire setup will be discussed at a later date. 
INL/EXT-09-16039 


\section{RESULTS}

Section 4 provides necessary properties data tested at INL's HTTL for all surrogate materials used in this INL/USU project. Section 4 also supplies experimental and simulation results for the two-thermocouple technique. Ultimately, a new section will be added to incorporate results from the hot wire technique.

\subsection{CFOAM25 Two-Thermocouple Results}

Provided in this section are testing results for CFOAM25 required material properties using the twothermocouple technique testing. Also, results for a 3-D generated CFOAM25 model using ABAQUS to calculate thermal conductivity of the test setup described in Section 3 are provide in this section.

\subsubsection{HTTL Measured CFOAM ${ }^{\circledR}$ Property Data}

Specialized systems existing at INL's HTTL were used to obtain temperature-dependent thermal conductivity for CFOAM25.

\subsubsection{Density Measurements}

For density estimates, three CFOAM25 samples were tested over a temperature range of 30 to $1000{ }^{\circ} \mathrm{C}$. Each sample had a different mass and length to assess the impact of sample size. The results of the dilatometer test are shown in Figure 4-1, where average density is plotted with measurement upper and lower limits.

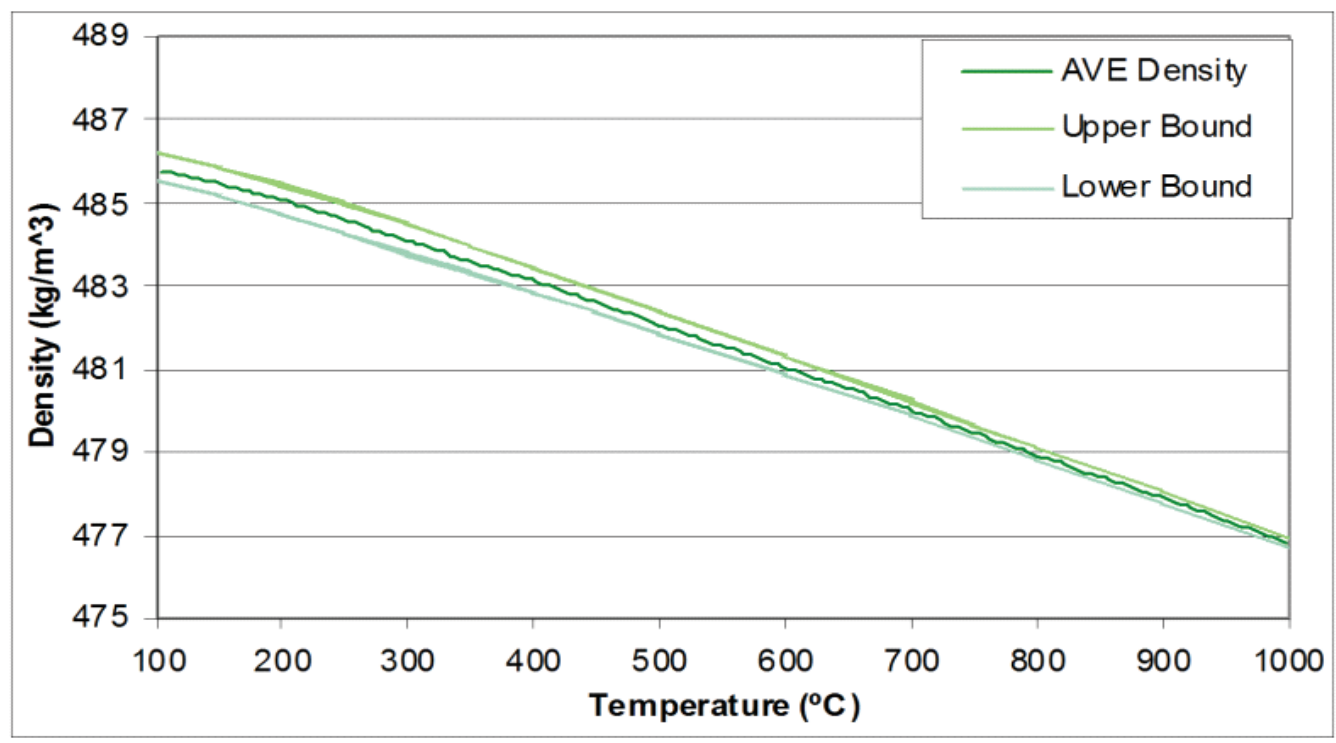

Figure 4-1. CFOAM25 average density versus temperature with upper and lower bounds

Figure 4-1 shows that the CFOAM25 density can be approximated linearly and that density changes for CFOAM25 are minimal (1.9\%) over the testing temperature range for the sample sizes evaluated. 


\subsubsection{Specific Heat Measurements}

CFOAM25 tests were completed using three machined samples and one sample crushed into powder form. The test temperatures ranged from 30 to $1000{ }^{\circ} \mathrm{C}$. An average was calculated from these tests, and results are shown in Figure 4-2 with upper and lower bounds.

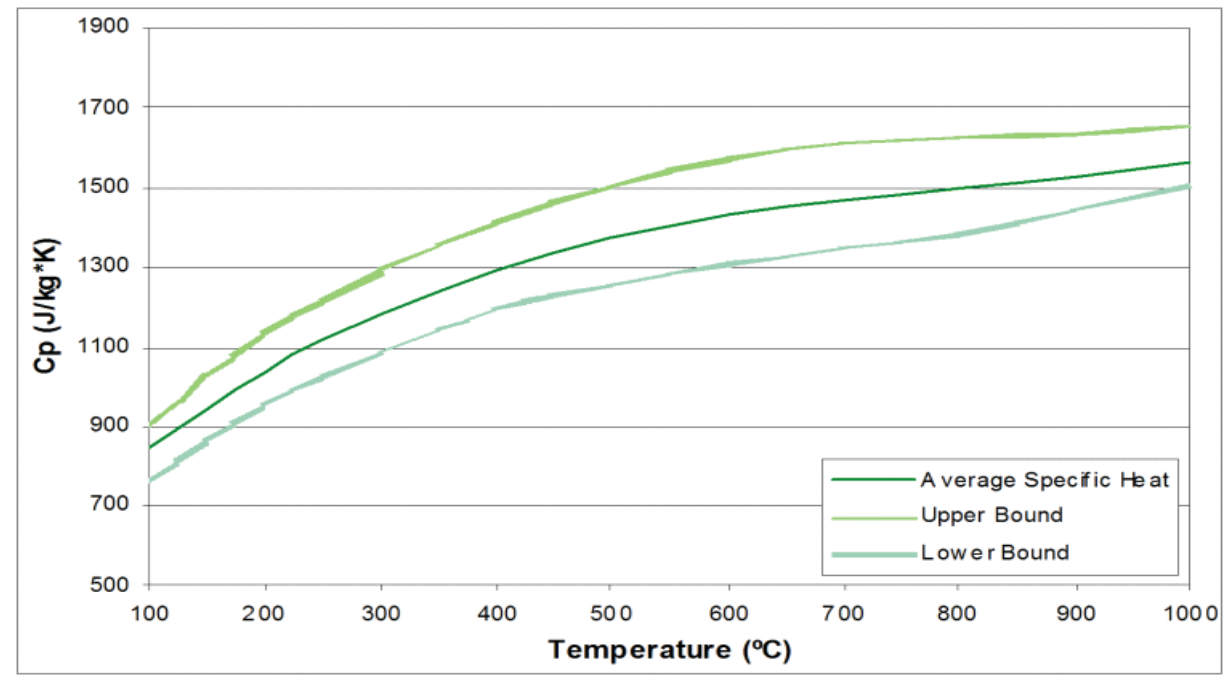

Figure 4-2. CFOAM25 average specific heat, $\mathrm{C}_{\mathrm{p}}$, vs. temperature with upper and lower bounds

The average value with upper and lower bounds was used in this effort to characterize the material's specific heat capacity. 


\subsubsection{Thermal Diffusivity Measurements}

Three CFOAM25 samples, with varying thickness, were tested twice to confirm repeatability. From this, it was also deduced that the properties of $\mathrm{CFOAM}^{\circledR}$ change very little when subjected to repeated tests over the testing temperature range of 30 to $1000^{\circ} \mathrm{C}$ as test-to-test variations were nearly undetectable. Figure 4-3 shows the average value of thermal diffusivity with its upper and lower limits.

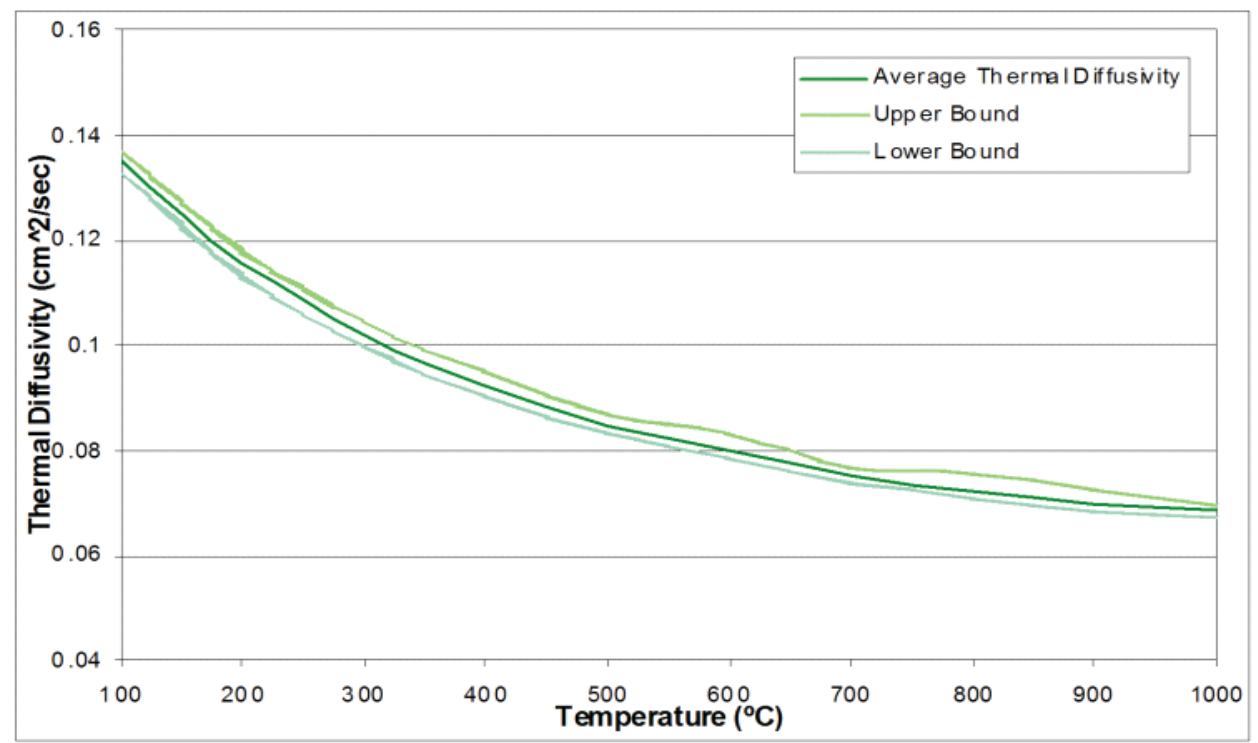

Figure 4-3. Average CFOAM25 thermal diffusivity vs. temperature with upper and lower bounds

\subsubsection{Thermal Conductivity From Material Properties Data}

The CFOAM25 thermal conductivity was calculated using average values obtained from CFOAM25 material property measurements for density, specific heat, and thermal diffusivity shown in Figures 4-1 through 4-3. Upper and lower estimates for material properties, which were based on upper and lower experimental values reported also in Figures 4-1 through 4-3, were no greater than 14\% from the estimated average values with upper values ranging between $8 \%-14 \%$ and lower values ranging between $6 \%-12 \%$.

\subsubsection{CFOAM25 Experimental Results}

Thermal conductivity testing, which began at INL's HTTL in January 2009, is still ongoing. Sensitivity testing from Table 3.1 are being considered, temperature variations, temperature gradient variations, and outer boundary condition variation have been tested. Two region cracked sample, multiple component, and contact resistance sensitivities are currently being considered with results to be given in the next progress report. However, initial testing appears promising with the setup shown in Figure 3-2. Early CFOAM25 results are compared in Figures 4-4 and 4-5 with average thermal conductivity values obtained from material property measurements. 


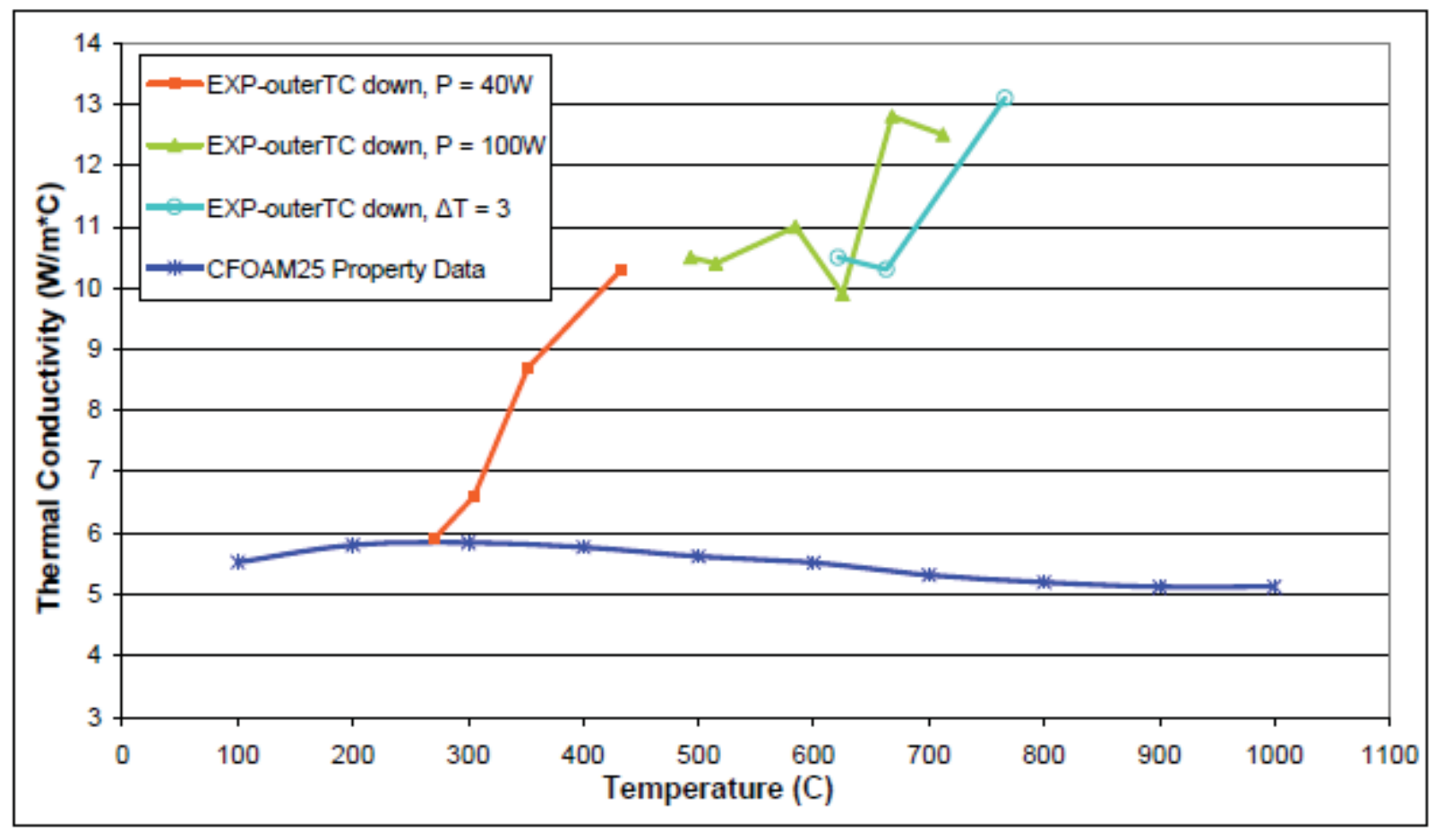

Figure 4-4. Two-thermocouple approach CFOAM25 outer thermocouple down experimental data

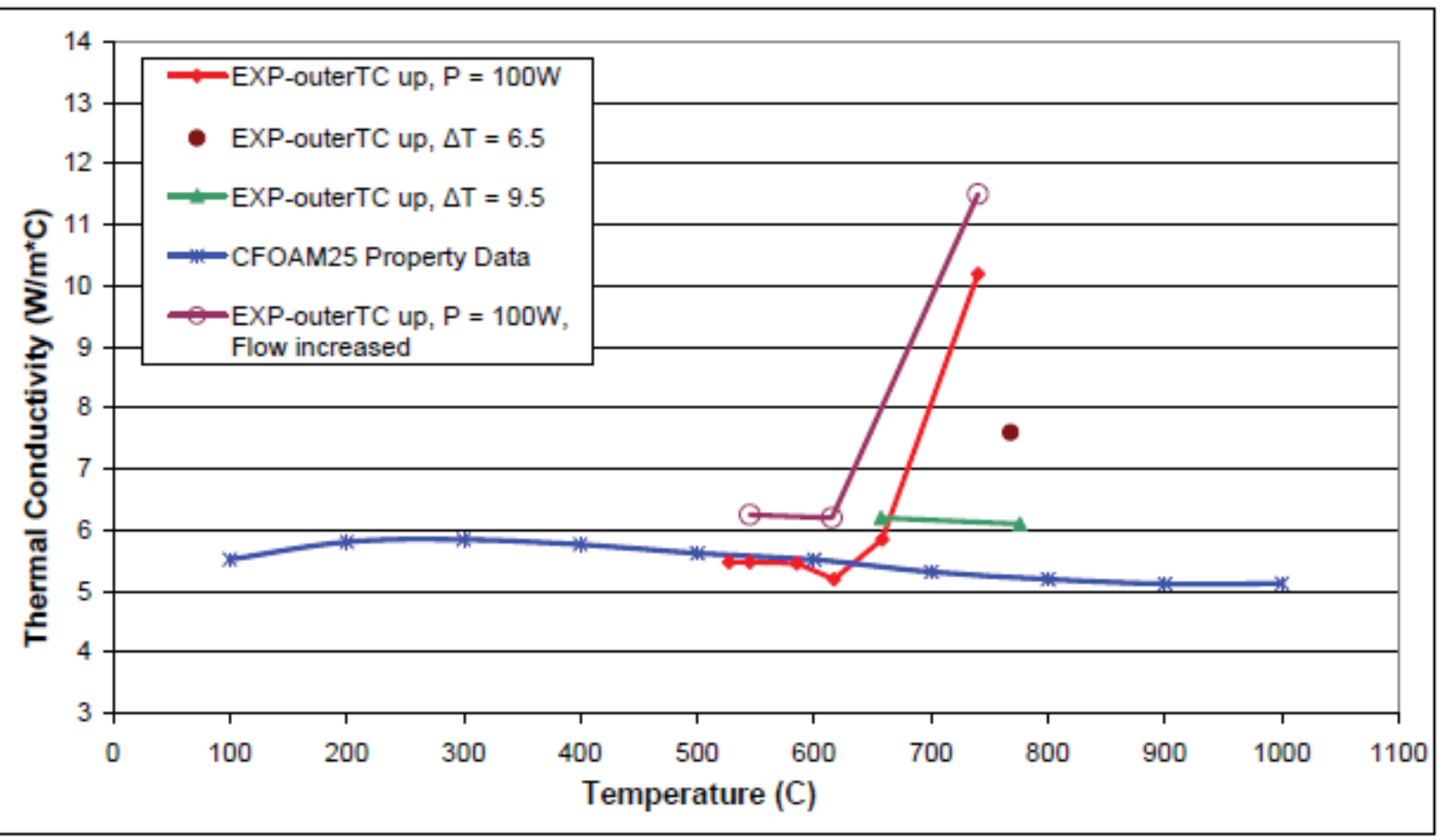

Figure 4-5. Two-thermocouple approach CFOAM25 outer thermocouple up experimental data 
Figures 4-4 and 4-5 show results from several parameter variations. Sample and furnace equilibrium temperature were observed to have a direct relationship to input power through the sample; larger supplied power and higher furnace temperatures yielded higher equilibrium temperatures for obtaining data. In general, data obtained at higher power levels and for lower furnace temperatures yielded larger temperature gradients through the samples. These larger temperature gradients, in turn, yielded thermal conductivity values more consistent with values obtained from material property systems at the HTTL.

Figure 4-4 displays results from three cases with the outer thermocouple directly below the centerline thermocouple. All three cases involved increasing furnace temperature. Two of the three cases had a supplied power constant at $40 \mathrm{~W}$ and $100 \mathrm{~W}$, while the third case had a constant temperature gradient of $3^{\circ} \mathrm{C}$. The $40 \mathrm{~W}$ series shows a quick divergence from the properties data, and the temperature gradient over the $40 \mathrm{~W}$ data series dropped from $2.5^{\circ} \mathrm{C}$ to under $1.5^{\circ} \mathrm{C}$. It is assumed that the temperature gradient over this data series was too low to have consistent and meaningful results. The $100 \mathrm{~W}$ series showed more consistent results, as conductivity values over the temperature range of 500 to $600{ }^{\circ} \mathrm{C}$ seem to stay between 10 $11 \mathrm{~W} / \mathrm{m}^{\circ} \mathrm{C}$. The temperature gradient for the last two data points of this series fell below $2^{\circ} \mathrm{C}$ from $3^{\circ} \mathrm{C}$, and this drop in $\Delta T$ is believed to cause these data points to diverge away from the $10-11 \mathrm{~W} / \mathrm{m}^{\circ} \mathrm{C}$ range. The first two data points from the case with $\Delta T=3^{\circ} \mathrm{C}$ showed conductivity results back into the $10-11 \mathrm{~W} / \mathrm{m}^{\circ} \mathrm{C}$ range. From this early testing, it was concluded that a temperature gradient greater than $3^{\circ} \mathrm{C}$ is desired to obtain consistent experimental data.

Testing with the outer thermocouple directly above the centerline thermocouple, as seen in Figure 4-5, yielded values more consistent with the properties data obtained at the HTTL. Four test cases are displayed in Figure 4-5, with all four cases holding supplied power or temperature gradient constant while increasing the furnace temperature and in one case also increasing tube flow rate. With supplied power constant at $100 \mathrm{~W}$, the results were close to the properties curve with a maximum deviation of $8 \%$ over the temperature range of 500 to $700{ }^{\circ} \mathrm{C}$. However, the data point above $700{ }^{\circ} \mathrm{C}$ diverged dramatically as $\Delta T$ fell from $6.6^{\circ}$ to $3^{\circ} \mathrm{C}$ when ambient (furnace) temperature increased. Measurements above $700{ }^{\circ} \mathrm{C}$ with the outer thermocouple directly above the centerline thermocouple improved as seen in the data series where $\Delta T=$ $6.5^{\circ} \mathrm{C}$ and also in the data series where $\Delta T=9.5^{\circ} \mathrm{C}$, especially over the temperature range of 750 to $800{ }^{\circ} \mathrm{C}$. When the power was held constant at $100 \mathrm{~W}$, the reading at $740^{\circ} \mathrm{C}$ was $92 \%$ away from the properties curve; but with $\Delta T=6.5^{\circ} \mathrm{C}$ and $9.5^{\circ} \mathrm{C}$, the reading dropped to $43 \%$ and $15 \%$, respectively.

There are several possible explanations for the diverging data shown in Figures 4-4 and 4-5. Observed differences due to thermocouple location may be due to angular dependence of outer thermocouple placement in the tube. ${ }^{5}$ As illustrated in Figure 4-6, it is possible for a plume to develop around the circumference of the rod due to boundary layer formation. Since the flow rate of argon through the tube was very low, an assumption of laminar flow around the cylinder can be valid. If the flow is laminar, then the Nusselt number can be described as a function of angle. Consider the defining equation for the Nusselt number, $h D / k$; where $h$ is the convective heat transfer coefficient, $D$ is the characteristic length (rod diameter in this case), and $k$ is the thermal conductivity of the fluid. Assuming that the thermal conductivity of the fluid along the exterior of the surrogate rod remains constant (see Figure 4-6), the only way the Nusselt number can decrease as angle $(\theta)$ increases is if the convective heat transfer coefficient increases. Measurements obtained with the initial setup indicate that thermal conductivity is larger when the outer thermocouple is down compared to when the outer thermocouple is up. That is, measurements suggest that larger temperature differences and associated heat flux occurred at the bottom then at the top. Hence, the plume in Figure 4-6 is a visual representation of heat transfer around the rod, where the observed heat transfer was lowest at the bottom. Figure 4-6 represents two dimensional flow and assumes the boundary layer development is 


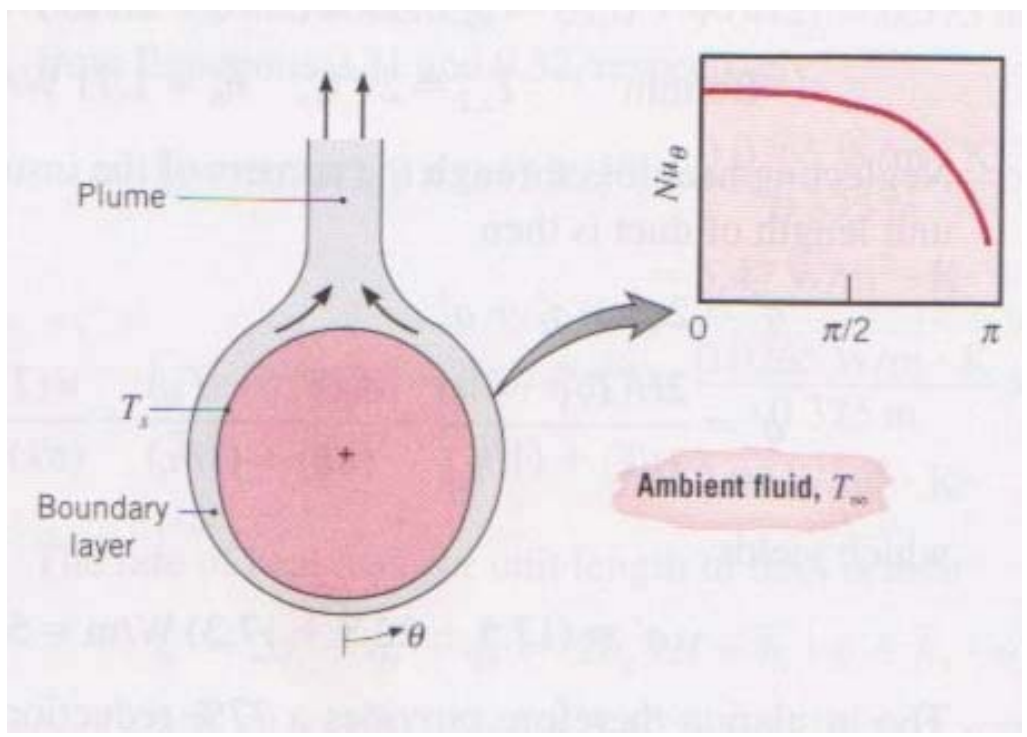

Figure 4-6. External free convection condition ${ }^{5}$

uniform; but in three dimensional flow the boundary layer of the sample is larger on the end closest to the tube exit and smallest on the end closest to the tube inlet. Increasing the argon flow within the tube increased the experimental conductivity measurement as seen from increased flow case in Figure 4-5. This increased flow supports a more developed boundary layer condition and consequently more heat transfer by convection away from the sample.

\subsubsection{CFOAM25 ABAQUS Results}

ABAQUS was used to model the performance of a surrogate fuel rod composed of CFOAM25 material. The components used in the model (surrogate fuel and thermocouples) were programmed with material properties obtained by testing and from manufacturers. The experimental conditions were then replicated within the model. This allowed for the comparison of experimental results with idealized results from the model.

\subsubsection{Base Case Results for $40 \mathrm{~W}$ and $100 \mathrm{~W}$}

Figure 4-7 shows base case results thermal conductivity estimates assuming a thermocouple-toCFOAM25 gap conductance value of $1643.75 \mathrm{~W} / \mathrm{m}^{2} \mathrm{~K}$ plotted against the average thermal conductivity from CFOAM25 HTTL property testing results. The legend notation in Figure 4-7 is: outer thermocouple gap coefficient - centerline thermocouple gap coefficient - supplied power (40 or $100 \mathrm{~W}$ ). As shown in this figure, ABAQUS results are consistent with, although slightly lower than, average values of measured material properties plotted in Figure 4-5 and experimental values obtained for cases with the outer thermocouple up (before data begin to diverge). Similar trends with temperature may be observed, although values calculated with ABAQUS are slightly lower due to the reduction in heat transfer from the gaps between the thermocouples and the CFOAM25. 


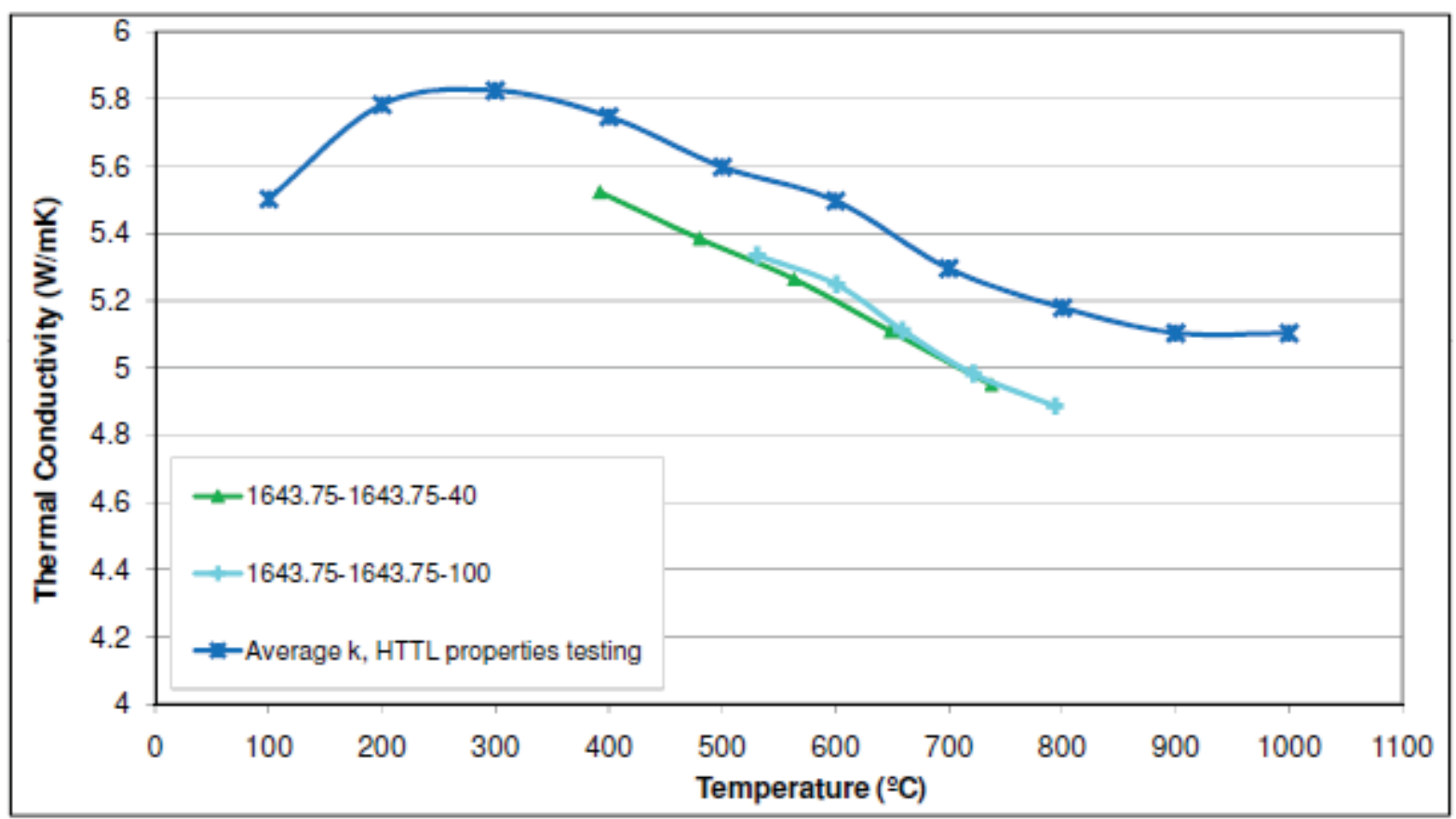

Figure 4-7. ABAQUS model base case CFOAM25 thermal conductivity outputs

\subsubsection{Gap Conductance Sensitivity}

Using CFOAM25 material properties and Equations in References 19 and 20, thermocouple to CFOAM gap conductances were calculated to range from 17.5 to $3270 \mathrm{~W} / \mathrm{m}^{2} \mathrm{~K}$. ABAQUS calculations were completed to assess the sensitivity of gap conductance for outer and centerline thermocouples for power inputs of $40 \mathrm{~W}$ and $100 \mathrm{~W}$ and ambient temperatures ranging from 400 to $800{ }^{\circ} \mathrm{C}$. Upper and lower bound estimates from ABAQUS calculations are compared with material property test results in Figure 48. 


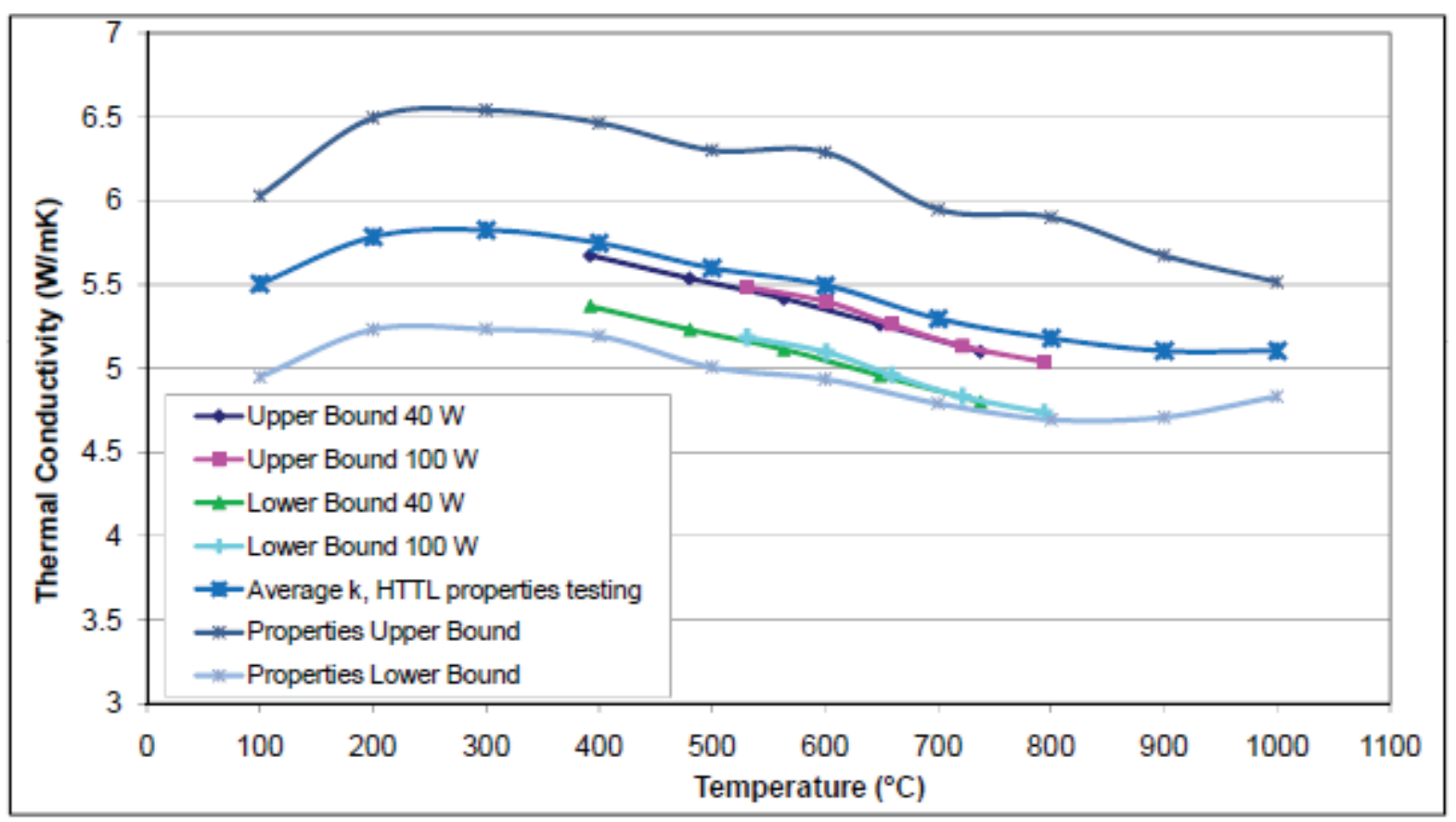

Figure 4-8. ABAQUS results compared to HTTL measured material properties

Several observations can be made from information presented in Figure 4-8. First, extreme variations in gap coefficients produce small, consistent variations in output thermal conductivity values. For example, the maximum value for gap coefficient of $3270 \mathrm{~W} / \mathrm{m} 2 \mathrm{~K}$ is approximately 187 times greater than the lowest estimate of $17.5 \mathrm{~W} / \mathrm{m} 2 \mathrm{~K}$. Although this factor of 187 increase in gap conductance did increase estimates for thermal conductivity, the increase was limited to approximately $6.4 \%$. Second, calculated values from Figure 4-8 are consistent with measured material property values and experimental values obtained for cases with the outer thermocouple up (before data begin to diverge). Third, comparisons reveal similar trends with temperature and that estimated values are within or slightly below estimated properties curve error bounds (although as noted in Section 4.1.3.1, the lower values are anticipated due to thermocoupleto-CFOAM gap heat transfer).

\subsubsection{Other Model Sensitivities}

Sensitivities testing using Table 2.3 is still being investigated and will be provided in the next progress report.

\subsection{Material 2 Two-Thermocouple Results}

Results to be given at a later date for material 2. 


\section{CONCLUSIONS}

Methods for in-pile detection of fuel rod thermal conductivity are being investigated using surrogate rod materials. As discussed in this initial progress report, evaluations are first being performed to investigate a method which uses two positioned thermocouples to measure the temperature of two points within the surrogate rod while Joule heating is applied to the rod for volumetric heat generation. Temperaturedependent thermophysical properties of elongation, specific heat, and thermal diffusivity, were measured using standard laboratory equipment to calculate thermal conductivity of the first surrogate rod material tested, CFOAM25. The test setup was modified to examine the sensitivity of results to several parameters, such as boundary condition changes, power supply variations, and temperature variations. Thermal conductivity was calculated under each condition to view the measurement sensitivity of method.

Key results documented in this initial progress report include:

- The thermal conductivity of the CFOAM25 rod was measured experimentally using a two-thermocouple method. For cases with the outer thermocouple located above the center thermocouple, values obtained for constant supplied power of $100 \mathrm{~W}$ between 500 to $700{ }^{\circ} \mathrm{C}$ were found to be within $2-8 \%$ from the values calculated using average values from standard material property measurement systems. In general, higher input values of power and $\Delta T$ measured with two thermocouples gave results closer to the properties curve. Values obtained experimentally are consistent with the values obtained from standard property measurement systems (see Figures 4-4 and 4-5) over a specific temperature range of 500 to $700{ }^{\circ} \mathrm{C}$. These values have similar trends and are within the upper and lower bounds obtained with laboratory material property measurement systems.

- Finite element calculations using ABAQUS were performed to verify and gain insights from experimental measurements. Results from steady state thermal conductivity predictions for CFOAM25 as a function of temperature were found to have similar trends and were within possible error ranges from the two thermocouple and HTTL material property system measured values. Sensitivities were completed with ABAQUS to evaluate the impact of gap resistance between the sample and thermocouples over a wide range of gap coefficients. Maximum variation from minimum and maximum gap coefficients was found to be $6.4 \%$.

While improvements to the method are currently being implemented, the proposed method's early test results suggest the viability of using surrogate fuel rods in a laboratory setting to gain insights and demonstrate possible improvements for currently used in-pile thermal conductivity measurement techniques. 
INL/EXT-09-16039 


\section{REFERENCES}

1. W. Wiesenack and T. Tverberg, "The OECD Halden Reactor Project Fuels Testing Programme: Selected Results and Plans," Nuclear Engineering and Design, 207, Issue 2, pp 189-197, 2001.

2. ASTM Standard C1113 - 99, "Standard Test Method for Thermal Conductivity of Refractories by Hot Wire (Platinum Resistance Thermometer Technique)," Reapproved 2004.

3. J. L. Rempe, K. G. Condie, and D. L. Knudson, Thermal Properties for Candidate SCWR Materials, INL/EXT-05-01030, December 2005.

4. ABAQUS/CEA, Version 6.8-2, Providence, Rhode Island, USA: Dassault Systèmes, 2008.

5. F. Incropera, et al., Fundamentals of Heat and Mass Transfer, John Wiley \& Sons, Inc., Hoboken USA (2007).

6. T. Beckwith, et al., Mechanical Measurements, Pearson Prentice Hall, Upper Saddle River USA (2007).

7. H. Thoresen and S. Solstad, "An overview of nuclear fuels and materials research at the OECD Halden Reactor Project," presented at INL, Idaho Falls, ID, July 15, 2008.

8. T. Tverberg, "In-Pile Fuel Rod Performance Characterisation in the Halden Reactor," Technical Meeting on "Fuel Rod Instrumentation and In-Pile Measurement Techniques," Halden, Norway, September 3-5, 2007.

9. A. L. E. F. Schleirmacher, Vher die Warmeleitungder gase, Weidemann Ann. Phys. 34, p. 625, 1988.

10. M. S. Baghe-Khandan, Y. Choi, and M. R. Okos, "Improved Line Heat Source Thermal Conductivity Probe," Journal of Food Science, 45, p 1430-1432, 1981.

11. J.J. Healy, J. J. de Groot, and J. Kestin, "The Theory of the Transient Hot-Wire Method for Measuring Thermal Conductivity," Physica, 82C, pp 392-408, 1976.

12. X-G Liang, "The Boundary Induced Error on the Measurement of Thermal Conductivity by Transient Hot Wire Method," Measurement Science Technology, 6, pp 467-471, 1995.

13. P. Prelovsek and B. Uran, "Generalized Hot Wire Method for Thermal Conductivity Measurements," J. Phs. E: Sci. Instrum., 17, 1984.

14. K. Manohar, D. W. Yarbrough, and J. R. Booth, "Measurement of Apparent Thermal Conductivity by the Thermal Probe Method," Journal of Testing and Evaluation, September 2000.

15. Anter Corporation, see www.anter.com.

16. M. F. Van Gelder, "A Thermistor Based Method for Measurement of Thermal Conductivity and Thermal Diffusivity of Moist Food Materials at High Temperatures," PhD Dissertation, Virginia Polytechnic Institute and State University, February 1998.

17. Touchtone Research Laboratory Webpage, www.cfoam.com. 
18. S. Kakac, Y. Yener, Heat Conduction, Taylor \& Francis Ltd., Philadelphia USA (1993)

19. J. Garnier, "Ex-Reactor Determination of Thermal and Contact Conductance," NUREG/CR-0330, 1979.

20. F. O. Goodman, "Progress in Surface Science," Volume 5, Part 3, 1974, Pages 261-375. 